\title{
FINAL REPORT- \\ GAS RETENTION AND RELEASE TESTS SUPPORTING THE CONCENTRATE RECEIPT VESSEL (CRV-VSL-00002A/2B) CONFIGURATION (U)
}

SEPTEMBER 2004

ENGINEERING DEVELOPMENT LABORATORY

HANFORD RIVER PROTECTION PROJECT - WTP

SAVANNAH RIVER NATIONAL LABORATORY

Westinghouse Savannah River Company

Savannah River Site

Aiken, SC 29808

Prepared for the U.S. Department of Energy Under Contract Number DEAC09-96SR18500

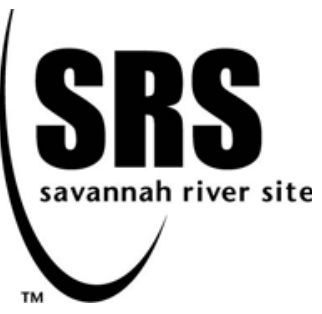


This document was prepared in conjunction with work accomplished under Contract No. DE-AC09-96SR18500 with the U. S. Department of Energy.

\section{DISCLAIMER}

This report was prepared as an account of work sponsored by an agency of the United States Government. Neither the United States Government nor any agency thereof, nor any of their employees, makes any warranty, express or implied, or assumes any legal liability or responsibility for the accuracy, completeness, or usefulness of any information, apparatus, product or process disclosed, or represents that its use would not infringe privately owned rights. Reference herein to any specific commercial product, process or service by trade name, trademark, manufacturer, or otherwise does not necessarily constitute or imply its endorsement, recommendation, or favoring by the United States Government or any agency thereof. The views and opinions of authors expressed herein do not necessarily state or reflect those of the United States Government or any agency thereof.

This report has been reproduced directly from the best available copy.

Available for sale to the public, in paper, from: U.S. Department of Commerce, National Technical Information Service, 5285 Port Royal Road, Springfield, VA 22161, phone: (800) 553-6847, fax: (703) 605-6900

email: orders@ntis.fedworld.gov

online ordering: http://www.ntis.gov/help/index.asp

Available electronically at http://www.osti.gov/bridge

Available for a processing fee to U.S. Department of Energy and its contractors, in paper, from: U.S. Department of Energy, Office of Scientific and Technical Information, P.O. Box 62, Oak Ridge, TN 37831-0062,

phone: (865)576-8401,

fax: (865)576-5728

email: $\underline{\text { reports@ adonis.osti.gov }}$ 
Key Words:

Pulse Jet Mixers

Gas Retention and Release

\section{Retention:}

Permanent

Key WTP R\&T References:

Test Specification

$$
\text { 24590-WTP-TSP-RT-03-011, Rev. } 0
$$

Test Plan WSRC-TR-2003-00532

Test Exceptions

24590-WTP-TEF-RT-04-006

Scoping Statement S-200

\section{FINAL REPORT- \\ GAS RETENTION AND RELEASE TESTS \\ SUPPORTING THE CONCENTRATE RECEIPT \\ VESSEL (CRV-VSL-00002A/2B) CONFIGURATION (U)}

\section{Hector N. Guerrero 786-5A \\ Kurt R. Eberl 773-A}

September 2004

Westinghouse Savannah River Company

Savannah River Site

Aiken, SC 29808

Prepared for the U.S. Department of Energy Under Contract Number DE-AC09-96SR18500

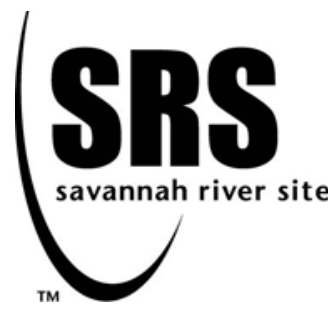


This page was intentionally left blank 


\section{TABLE OF CONTENTS}

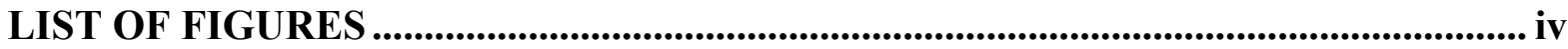

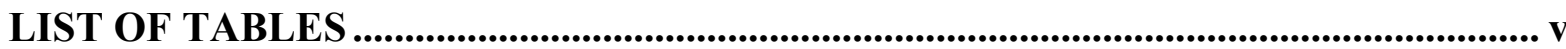

LIST OF ACRONYMS ..................................................................................................... vi

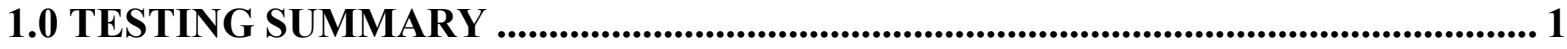

1.1 OBJECTIVES............................................................................................................. 2

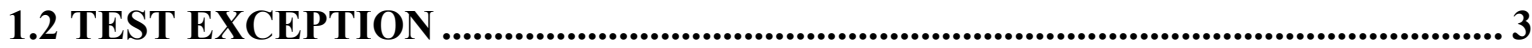

1.3 RESULTS AND PERFORMANCE AGAINST SUCCESS CRITERIA .................. 3

1.4 QUALITY REQUIREMENTS.................................................................................... 3

1.5 R\&T TEST CONDITIONS ............................................................................................. 4

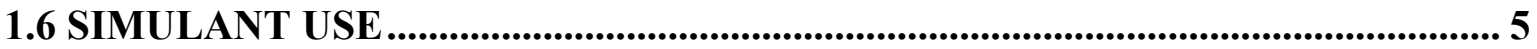

1.6.1 Plant Bounding Conditions .............................................................................................. 5

1.6.1.1 Normal Plant Operation Rheological Bound ...................................................... 5

1.6.1.2 Plant Upset Operation Rheological Bound........................................................... 7

1.6.2 Simulants......................................................................................................................... 7

1.7 DISCREPANCIES AND FOLLOW-ON TESTS .................................................. 8

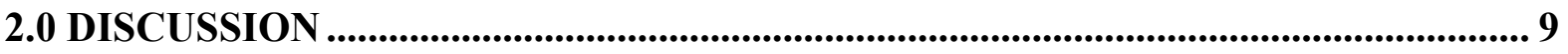

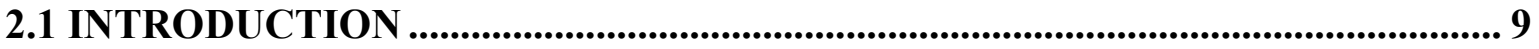

2.2 PRINCIPLE AND APPROACH................................................................................... 10

2.3 QA PROGRAM ................................................................................................................ 11

2.3.1 CRV Vessel and PJM Configuration............................................................................. 11

2.3.2 System Operation and Data Acquisition System....................................................... 16

2.3.3 Tank Level Measurement............................................................................................. 17

2.4 TEST METHODS.......................................................................................................... 17

2.4.1 Gas Holdup Tests ........................................................................................................ 17

2.4.2 Gas Release Tests .............................................................................................. 18

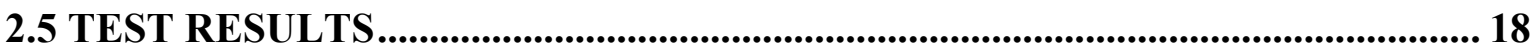

2.5.1 Gas Retention Under Various $\mathrm{H}_{2} \mathrm{O}_{2}$ Injection Rates ............................................ 18

2.5.2 Gas Holdup in Normal Operations............................................................................ 19

2.5.3 Gas Release after Mixing System Restart ................................................................ 22

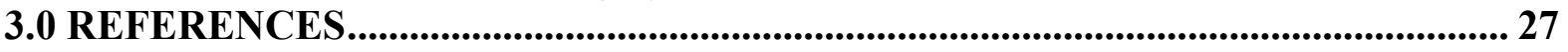


WSRC-TR-2004-00399, REVISION 0

SRNL-RPP-2004-00062, REVISION 0

\section{LIST OF FIGURES}

Figure 1-1. Rheogram of Actual HLW Pretreated Sludge Samples with Upper Bound

Rheological Curve

Figure 1-2. Flow Behavior Comparison of PJM Simulants and Actual HLW Pretreated

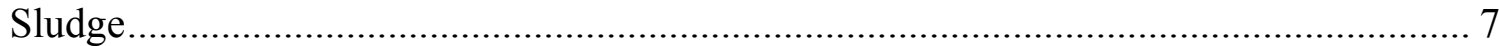

Figure 2-1. Top View of the CRV Prototypic Test Stand Showing Nominal Dimensions .. 12

Figure 2-2. Plan View of the CRV Test Stand Showing Nominal Dimensions ................... 13

Figure 2-3. Center Nozzle Showing Nominal Dimensions for 1-inch Nozzle ...................... 14

Figure 2-4. $45^{\circ}$ Nozzle; Showing Nominal Dimensions for I-inch Nozzle............................ 14

Figure 2-5. $135^{\circ}$ Nozzle Showing Nominal Dimensions for 1-inch Nozzle ........................ 15

Figure 2-6. Sparger and Sample Line Locations in Final "Chandelier" Arrangement ......... 16

Figure 2-7. Gas Fraction as a Function of Time after Batch Injection of $\mathrm{H}_{2} \mathrm{O}_{2}$ in Three Gas

Holdup Tests in the CRV .....

Figure 2-8. Gas Fraction as a Function of Time During and After Continuous $\mathrm{H}_{2} \mathrm{O}_{2}$

Injection in the CRV Prototype (Test B-7).

Figure 2-9. Gas Fraction as a Function of Time During and After Continuous $\mathrm{H}_{2} \mathrm{O}_{2}$

Injection in the CRV Prototype (Test E-2)..................................................................... 21

Figure 2-10. Gas Fraction as a Function of Time During and After a Gas Holdup Test in the

CRV Prototype (Test E-4).

Figure 2-11. Gas Release from Gelled Clay in the CRV Prototype after Gas Holdup in

Figure 2-7 (Test B-7, six PJMs, 3 upwards 1.5" nozzles and 3 downwards 1.5" nozzles)

Figure 2-12. Gas Release from Gelled Clay in the CRV Prototype after Gas Holdup in

Figure 2-7 (Test E-2, six PJMs, 1" downward nozzles+ 3 spargers @ 1.9 scfm ea.)..... 23

Figure 2-13. Gas Release from Gelled Clay in the CRV Prototype after Gas Holdup in

Figure 2-7 (Test E-4, six PJMs, 3 upwards 1.5" nozzles and 3 downwards 1.5" nozzles)

Figure 2-14. Gas Release from Gelled Clay in the CRV Prototype after Gas Holdup in

Figure 2-9 (Test E-2, six PJMs + three spargers at 1.9 scfm ea)

Figure 2-15. Gas Release from Gelled Clay in the CRV Prototype after Gas Holdup in

Figure 2-10 (Test E-4, 3 upward and 3 downward 1.5" nozzles + five spargers at 1.8

scfm ea) 


\section{LIST OF TABLES}

Table 1-1. Test Objectives from Test Specification 24590-WTP-TSP-RT-03-011, Rev. 0... 2

Table 1-2. Test Exception............................................................................................ 3

Table 1-3. Test Results Compared to Expected Plant Conditions ........................................ 3

Table 1-4. CRV Mixing System Configurations and Test Conditions for GR\&R Testing .... 5

Table 1-5. Physical and Rheological Properties that Help Define Simulants for Rating or

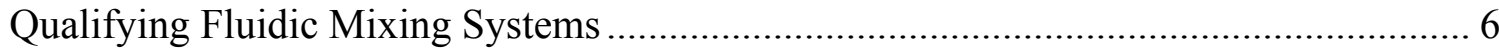

Table 1-6. Rheological Model Fits for CRV Prototype PJM Simulants at Ambient

Temperature

Table 2-1. Hydrogen Peroxide Injection Rates for Gas Holdup Tests ............................... 18

Table 2-2. Experimental Gas Release and Holdup in the CRV Test Stand Under Normal

Operating Conditions .......................................................................................... 22 


\section{LIST OF ACRONYMS}

$\begin{array}{ll}\text { BNI } & \text { Bechtel National, Inc. } \\ \text { CCN } & \text { correspondence control number } \\ \text { CRV } & \text { concentrate receipt vessel } \\ \text { DACS } & \text { data acquisition and control software } \\ \text { DBE } & \text { design basis event } \\ \text { GR\&R } & \text { gas retention and release } \\ \text { H/D } & \text { ratio of slurry height to vessel diameter } \\ \text { HLW } & \text { high-level waste } \\ \text { ID } & \text { inner diameter } \\ \text { JPP } & \text { jet pump pair } \\ \text { OD } & \text { outer diameter } \\ \text { PJM } & \text { pulse jet mixer } \\ \text { R\&D } & \text { research and development } \\ \text { R\&T } & \text { research and technology } \\ \text { RD } & \text { rheological additive } \\ \text { RFD } & \text { reverse flow diverter } \\ \text { ROB } & \text { region of bubbles } \\ \text { scfm } & \text { standard cubic feet per minute } \\ \text { VVV } & \text { Validate, Verify, nozzle Velocity } \\ \text { WTP } & \text { Waste Treatment Plant } \\ \text { ZOI } & \text { zone of influence }\end{array}$


WSRC-TR-2004-00399, REVISION 0

SRNL-RPP-2004-00062, REVISION 0

\subsection{TESTING SUMMARY}

Gas Retention and Release (GR\&R) tests were performed in the scaled Concentrate Receipt Vessel (CRV) Test Stand at the Savannah River National Laboratory to validate the capability of candidate Hybrid-Mixing systems for the CRV to safely release hydrogen during normal and upset conditions. Hydrogen is generated in the radioactive waste as a result of natural and plant processes and must not be allowed to accumulate above flammability limits. Two types of tests were conducted. Gas holdup tests determined the steady state amount of gas accumulated in the simulant under normal PJM only or PJM plus sparging conditions. Gas release tests determined what operating conditions are necessary to fully release gas after a steady state gas fraction of $4 \%$ tank volume or more was reached in the simulant.

Three CRV configurations were tested:

1. 3 PJMs with 1.5-inch upward facing $\left(135^{\circ}\right)$ nozzles, 2 PJMs with downward-facing $45^{\circ}$ nozzles, 1 center downward nozzle (no spargers)

2. 5 PJMs with 1-inch nozzles facing downward and 1 center downward nozzle (5 spargers)

3. 5 PJMs with 1-inch nozzles facing downward and 1 center downward nozzle (no spargers)

For test purposes, hydrogen gas generation was simulated by the breakdown of hydrogen peroxide into oxygen gas and water in the kaolin:bentonite simulant. First, a steady state gas fraction simulating accumulated gas after an extended period of plant shutdown was achieved by mixing in a batch injection of $30 \mathrm{wt} \%$ hydrogen peroxide (Sec. 3.5.1). After an overnight growth period, the PJMs/spargers were restarted and the change in level measured by the use of laser sensors. Second, the rate of change and steady state value of the gas fraction during continuous injection of hydrogen peroxide was measured with the PJMs/spargers operating (Sec. 3.5.2). Gas release tests were also performed to determine the rate of release of gas after the batch and continuous injections (Sec. 3.5.3) with PJMs and sparging operating singly or combined.

The tests on Configuration 1 showed that the maximum holdup after batch injection of 1325 gm of $\mathrm{H}_{2} \mathrm{O}_{2}$ solution was $16.3 \%$. After slow and fast (continuous) injection of hydrogen peroxide, the maximum holdup was $13.6 \%$ and $23.6 \%$, respectively, which was due to the total amount of $\mathrm{H}_{2} \mathrm{O}_{2}$ (1325 and 2800 gms, respectively) injected. During continuous $\mathrm{H}_{2} \mathrm{O}_{2}$ injection of $8 \mathrm{ml} / \mathrm{min}$ and $16 \mathrm{ml} / \mathrm{min}$ of $\mathrm{H}_{2} \mathrm{O}_{2}$ solution, corresponding to the slow and fast injection rates above, a maximum holdup of $0.5 \%$ and rates of increase of $0.005 \% / \mathrm{min}$ were observed for both cases. Upon restarting the PJMs/spargers, $95 \%$ of the accumulated gas was released after 20 cycles. 
The tests on Configuration 2 exhibited a 5.5\% maximum holdup after batch injection of $664 \mathrm{gm} \mathrm{H}_{2} \mathrm{O}_{2}$ solution. All of the gas accumulated was released after 20 cycles of $\mathrm{PJM} /$ sparger operation. During continuous injection simulating normal operating conditions, the rate of rise of the gas fraction was $0.028 \% / \mathrm{min}$ and the maximum holdup was $2 \%$. After the PJMs/spargers were turned off, a maximum holdup of $7.5 \%$ developed. This decreased to $1.25 \%$ after restarting the spargers only. The gas was completely released only when the PJMs were also restarted.

The tests on Configuration 3 determined a maximum holdup of $4.9 \%$ after batch injection of $664 \mathrm{gm}$ of $\mathrm{H}_{2} \mathrm{O}_{2}$ solution. The accumulated gas was released after 20 cycles of $\mathrm{PJM} / \mathrm{sparger}$ operation. Holdup testing simulating normal operating conditions $(28 \mathrm{ml} / \mathrm{min}$ of $30 \mathrm{wt} \%$ $\mathrm{H}_{2} \mathrm{O}_{2}$ solution) showed a rate of increase of the gas fraction of $0.2 \% / \mathrm{min}$ and a maximum holdup of $1 \%$. The gas accumulated after the PJMs/spargers were turned off amounted to $7.5 \%$, which was completely released after 20 cycles (8 minutes) when the PJMs/spargers were restarted.

\subsection{OBJECTIVES}

The test objectives from Test Specification 24590-WTP-TSP-RT-03-011, Rev. 0 are shown in Table 1-1:

Table 1-1. Test Objectives from Test Specification 24590-WTP-TSP-RT-03-011, Rev. 0

\begin{tabular}{|c|c|c|}
\hline Test Objective & $\begin{array}{l}\text { Objective } \\
\text { Met (Y/N) }\end{array}$ & Discussion \\
\hline $\begin{array}{l}\text { 1. Measure gas hold-up levels } \\
\text { during steady state operation } \\
\text { using vessels that have } \\
\text { demonstrated sufficient } \\
\text { mobilization of the } \\
\text { simulant(s) }\end{array}$ & $\mathrm{Y}$ & $\begin{array}{l}\text { Three sets of GR\&R tests were } \\
\text { performed on three different CRV } \\
\text { mixing systems that simulated gas } \\
\text { holdup during steady state } \\
\text { operation. For all test sets, the gas } \\
\text { holdup was measured while PJMs } \\
\text { and spargers were operating. The } \\
\text { maximum steady state holdup did } \\
\text { not exceed } 2 \% \text {. }\end{array}$ \\
\hline $\begin{array}{l}\text { 2. Measure gas release } \\
\text { characteristics to allow } \\
\text { Engineering to define PJM } \\
\text { operating parameters that can } \\
\text { be adopted into the WTP } \\
\text { design basis to assure that the } \\
\text { PJMs and vessel ventilation } \\
\text { systems can sustain safe } \\
\text { operation. }\end{array}$ & Y & $\begin{array}{l}\text { Three sets of GR\&R tests were } \\
\text { performed on three different CRV } \\
\text { mixing systems that simulated gas } \\
\text { release after loss-of-power events. } \\
\text { For all tests, the accumulated gas } \\
\text { was released within } 40 \text { cycles of } \\
\text { PJM and sparger restart operation. }\end{array}$ \\
\hline
\end{tabular}




\subsection{TEST EXCEPTION}

The test exception is shown in Table 1-2:

Table 1-2. Test Exception

\begin{tabular}{|l|l|}
\hline List Test Exceptions & Describe Test Exceptions \\
\hline $1.24590-$ WTP-TEF-RT-04-00006 [3] & Provided test conditions for two \\
& PJM/sparger configurations to be tested. \\
& No impact on the objectives. \\
\hline
\end{tabular}

\subsection{RESULTS AND PERFORMANCE AGAINST SUCCESS CRITERIA}

Test results are compared to expected plant conditions in Table 1-3.

Table 1-3. Test Results Compared to Expected Plant Conditions

\begin{tabular}{|l|l|}
\hline List Success Criteria & $\begin{array}{l}\text { Explain How the Tests Did or Did Not } \\
\text { Meet the Success Criteria }\end{array}$ \\
\hline $\begin{array}{l}\text { 1. These tests will be deemed successful if } \\
\text { gas hold-up levels are measured during } \\
\text { steady state PJM operation using vessels } \\
\text { that have demonstrated sufficient } \\
\text { mobilization of the simulant(s) under } \\
\text { prototypic PJM operating conditions. }\end{array}$ & $\begin{array}{l}\text { A set of GR\&R tests was performed on } \\
\text { each of three different CRV mixing } \\
\text { systems that simulated gas hold up during } \\
\text { steady state operation. For all test sets, the } \\
\text { gas holdup was measured while PJMs and } \\
\text { spargers were operating. }\end{array}$ \\
\hline $\begin{array}{l}\text { 2. These tests will be deemed successful if } \\
\text { applicable gas release characteristics are } \\
\text { measured after loss-of-power events. }\end{array}$ & $\begin{array}{l}\text { A set of GR\&R tests was performed on } \\
\text { each of three different CRV mixing } \\
\text { systems, respectively, that simulated gas } \\
\text { release after loss-of-power events. }\end{array}$ \\
\hline
\end{tabular}

\subsection{QUALITY REQUIREMENTS}

This work was conducted in accordance with the RPP-WTP QA requirements specified for work conducted by SRTC as identified in DOE IWO MOSRLE60. SRTC has provided matrices to WTP demonstrating compliance of the SRTC QA program with the requirements specified by WTP. Specific information regarding the compliance of the SRTC QA program with RW-0333P, Revision 10, NQA-1 1989, Part 1, Basic and Supplementary Requirements and NQA-2a 1990, Subpart 2.7 is contained in these matrices. 


\subsection{R\&T TEST CONDITIONS}

The Test Specification establishes conditions to ensure that results are valid for project needs. This section lists those conditions and indicates whether they were followed. It describes the circumstances and consequences where deviations may have been necessary.

\begin{tabular}{|c|c|}
\hline List R\&T Test Conditions & Were Test Conditions Followed? \\
\hline $\begin{array}{l}\text { 1. Holdup tests involve the generation of } \\
\text { gas bubbles in simulant waste in scaled } \\
\text { vessels during prototypic PJM operation. } \\
\text { The holdup (fraction of gas retained in } \\
\text { simulant) will be measured as a function of } \\
\text { generation rate in prototypic vessels or a } \\
\text { single representative vessel, as required to } \\
\text { meet the testing schedule, (e.g., the gas } \\
\text { release and retention vessel). The gas } \\
\text { hold-up will be determined by means of } \\
\text { surface level changes. A minimum of four } \\
\text { scaled gas holdup tests are planned, one } \\
\text { using a representative particulate simulant } \\
\text { and three using Laponite simulants based } \\
\text { on two gas generation rates and two } \\
\text { consistencies. }\end{array}$ & $\begin{array}{l}\text { Only the particulate simulant } \\
\text { (kaolin:bentonite) tests were performed } \\
\text { since the method of generating hydrogen } \\
\text { relied on hydrogen peroxide on the clay } \\
\text { particles. Three CRV mixing systems } \\
\text { were evalutated. In one mixing system, } \\
\text { three gas generation rates were tested. } \\
\text { Two rheologies were tested, but in } \\
\text { different mixing systems. }\end{array}$ \\
\hline $\begin{array}{l}\text { 2. Tests will involve generating bubbles in } \\
\text { stationary, unmixed simulant, and then } \\
\text { measuring the release rate by means of } \\
\text { either surface level changes (primary } \\
\text { candidate) or a controlled ventilation of } \\
\text { headspace gas and associated gas } \\
\text { composition determinations (secondary } \\
\text { alternative) after restart of the PJMs in } \\
\text { normal pulsed operating mode. A } \\
\text { minimum of four scaled gas holdup tests } \\
\text { are planned, one using a representative } \\
\text { particulate simulant and three using } \\
\text { Laponite simulants based on two gas } \\
\text { generation rates and two consistencies. }\end{array}$ & $\begin{array}{l}\text { Only the particulate simulant } \\
\text { (kaolin:bentonite) tests were performed } \\
\text { since the method of generating hydrogen } \\
\text { relied on hydrogen peroxide on the clay } \\
\text { particles. Three CRV mixing systems } \\
\text { were evalutated. In all of the mixing } \\
\text { systems, two gas release rates were tested. } \\
\text { Two rheologies were tested (different } \\
\text { mixing systems). }\end{array}$ \\
\hline
\end{tabular}


WSRC-TR-2004-00399, REVISION 0

SRNL-RPP-2004-00062, REVISION 0

Table 1-4 lists the specific test conditions communicated to SRNL (orally) and via Test Exception 24590-WTP-TEF-RT-04-00006, Rev. 0.

Table 1-4. CRV Mixing System Configurations and Test Conditions for GR\&R Testing

\begin{tabular}{|c|c|c|c|c|c|c|c|c|c|}
\hline \multirow[b]{2}{*}{$\begin{array}{c}\text { Test } \\
\text { Group }\end{array}$} & \multirow[b]{2}{*}{$\begin{array}{c}\text { Test } \\
\text { Sequence }\end{array}$} & \multirow[b]{2}{*}{ Test type } & \multicolumn{3}{|c|}{ Nozzle Configuration } & \multirow[b]{2}{*}{$\begin{array}{l}\text { Nozzle } \\
\text { I.D., } \\
\text { inches }\end{array}$} & \multirow{2}{*}{\begin{tabular}{|c|} 
Nominal \\
Nozzle \\
Velocity \\
$\mathbf{m} / \mathbf{s}$ \\
\end{tabular}} & \multirow{2}{*}{$\begin{array}{c}\# \\
\text { (Spargers) } \\
\text { a scfm } \\
\text { tot. }\end{array}$} & \multirow{2}{*}{$\begin{array}{c}\text { Nominal } \\
\text { Yield } \\
\text { Stress } \\
(\mathbf{P a})\end{array}$} \\
\hline & & & $\begin{array}{l}\# 45 \\
\text { deg. }\end{array}$ & $\begin{array}{c}\# 135 \\
\text { deg. }\end{array}$ & \begin{tabular}{|c|}
$\#$ \\
Vertica \\
1 \\
\end{tabular} & & & & \\
\hline B & 7 & PJM only & 2 & 3 & 1 & 1.5 & 8 & N/A & 20 \\
\hline$E$ & 2 & $\begin{array}{c}\text { PJM + } \\
\text { sparging }\end{array}$ & 5 & N/A & 1 & 1 & 12 & (3) 6 & 30 \\
\hline $\mathrm{E}$ & 4 & $\begin{array}{c}\text { PJM + } \\
\text { sparging }\end{array}$ & 2 & 3 & 1 & 1 & 12 & (5) 9 & 30 \\
\hline
\end{tabular}

\subsection{SIMULANT USE}

\subsubsection{Plant Bounding Conditions}

For the CRV vessel which will contain non-Newtonian fluids, it was assumed that the HLW pretreated sludge bounding physical and rheological properties would hold (CCNs 069099, 065607, and 082255).

\subsubsection{Normal Plant Operation Rheological Bound}

Data from actual radioactive and simulant waste rheograms combined with general engineering principles were used to define a set of bounding physical and rheological properties that agree well with actual data (Poloski et al. 2003). The non-Newtonian HLW pretreated sludge rheological properties were fit using a linear Bingham plastic model. The bounding conditions were used to develop the waste simulants used in the PJM program. Figure 1-1 is a plot of actual pretreated waste rheograms and the upper bounding rheological properties curve. The linear Bingham plastic model fit parameters are yield stress (y-axis intercept) of $30 \mathrm{~Pa}$ and consistency (slope) of $30 \mathrm{cP}$. Table $1-5$ contains a summary of expected physical and rheological properties.

Because the rheological window is based on only four samples from three tanks, it is possible that slurries from other tanks could exceed the rheological boundary. It has been estimated that 20 to $30 \%$ of HLW tanks may have rheological properties higher (yield stress and consistency higher than $30 \mathrm{~Pa}$ and $30 \mathrm{cP}$, respectively) than those documented in the three active tank samples analyzed to date (CCN 082255). This uncertainty will be addressed by laboratory testing prior to receipt of the waste at the WTP to define the extent to which the slurry may be concentrated and stay below the rheological boundary. 
WSRC-TR-2004-00399, REVISION 0

SRNL-RPP-2004-00062, REVISION 0

Table 1-5. Physical and Rheological Properties that Help Define Simulants for Rating or Qualifying Fluidic Mixing Systems

\begin{tabular}{|l|c|}
\hline \multicolumn{1}{|c|}{ Property } & HLW Pretreated Sludge \\
\hline $\mathrm{pH}$ & $\approx 12^{(\mathrm{a})}-14$ \\
\hline Particle size distribution $\left(\mathrm{D}_{50}\right)^{(\mathrm{b})}$ & $2 \mu \mathrm{m}$ \\
\hline Particle size distribution $\left(\mathrm{D}_{95}\right)^{(\mathrm{c})}$ & $20 \mu \mathrm{m}$ \\
\hline Bulk density & $1.1-1.6$ \\
\hline Supernatant liquid density & $\approx 1.0$ \\
\hline Vol\% settled solids & $5 \%-25 \%$ \\
\hline $\mathrm{Wt} \%$ total dried solids & $7 \%-15 \%$ \\
\hline $\mathrm{Wt} \%$ total oxide & Bingham Plastic \\
\hline Shear stress versus shear rate $\left(\right.$ ambient and $\left.40^{\circ} \mathrm{C}\right)$ & \\
\hline $\begin{array}{l}\text { (a) Expected pH after washing leaching in } 0.01 \mathrm{M} \mathrm{NaOH} . \\
\text { (b) } 50 \% \text { of particles are smaller than the indicated value. } \\
\text { (c) } 95 \% \text { of particles are smaller than the indicated value. } \\
\text { (d) Based on simulant data. }\end{array}$ \\
\hline
\end{tabular}

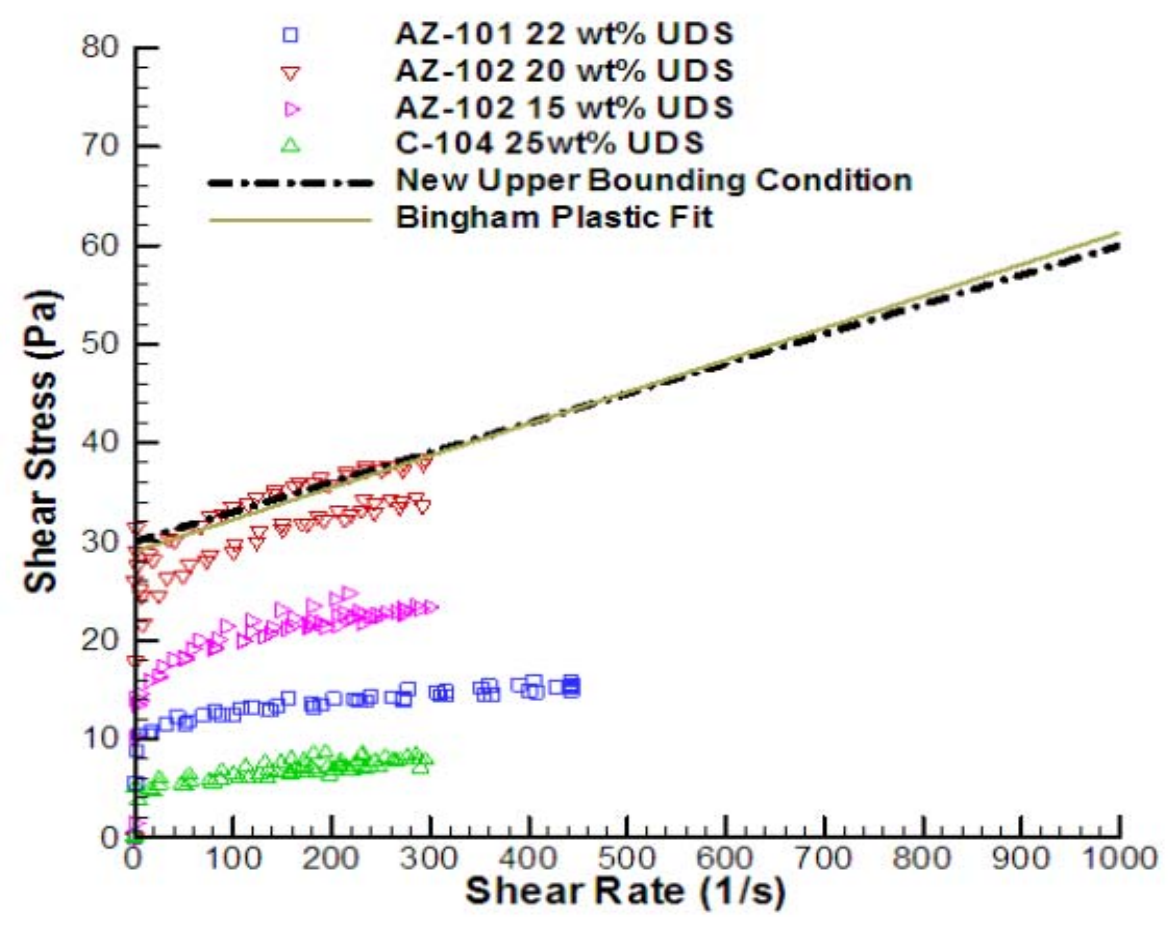

Figure 1-1. Rheogram of Actual HLW Pretreated Sludge Samples with Upper Bound Rheological Curve 


\subsubsection{Plant Upset Operation Rheological Bound}

It is important to note that for actual HLW pretreated sludge samples when allowed to stand in an unmixed condition, that is, post-DBE, the waste will gel and reach maximum shear strength values greater than $30 \mathrm{~Pa}$. For this reason, a bounding shear strength value of $70 \mathrm{~Pa}$ should be used (CCN 065607). In addition, the "gel" time (time required for the actual waste to reach its maximum shear strength) must be taken into account along with the maximum shear strength for plant operation considerations.

\subsubsection{Simulants}

One transparent simulant and one opaque simulant were used in the PJM program. The transparent simulant was Laponite RD (Southwestern Clay Products), a thixotropic colloidal synthetic clay that forms stable gel networks when unsheared. Due to the thixotropic nature of Laponite, the flow behavior of the simulant is dynamic, and it was allowed to gel and reach a target shear strength. Speers et al. (1987) demonstrated that the shear strength of clay drilling muds increases over time following first-order rate kinetics. Laponite shear strength behavior was observed to agree with the Speers et al. (1987) correlation for drilling muds. At this point the PJM system was started and a mixing cavern formed as defined by the gel's shear strength. After constant shearing, a steady-state flow behavior was approached. Unfortunately, this flow behavior was lower than the bounding rheology of WTP waste streams. This is illustrated in Figure 1-2, where actual HLW pretreated sludge rheograms are compared with PJM simulants. The bounding rheological parameters of the HLW pretreated sludge (Poloski et al. 2003) are defined as Bingham plastic consistency of $30 \mathrm{cP}$ and yield stress of $30 \mathrm{~Pa}$.

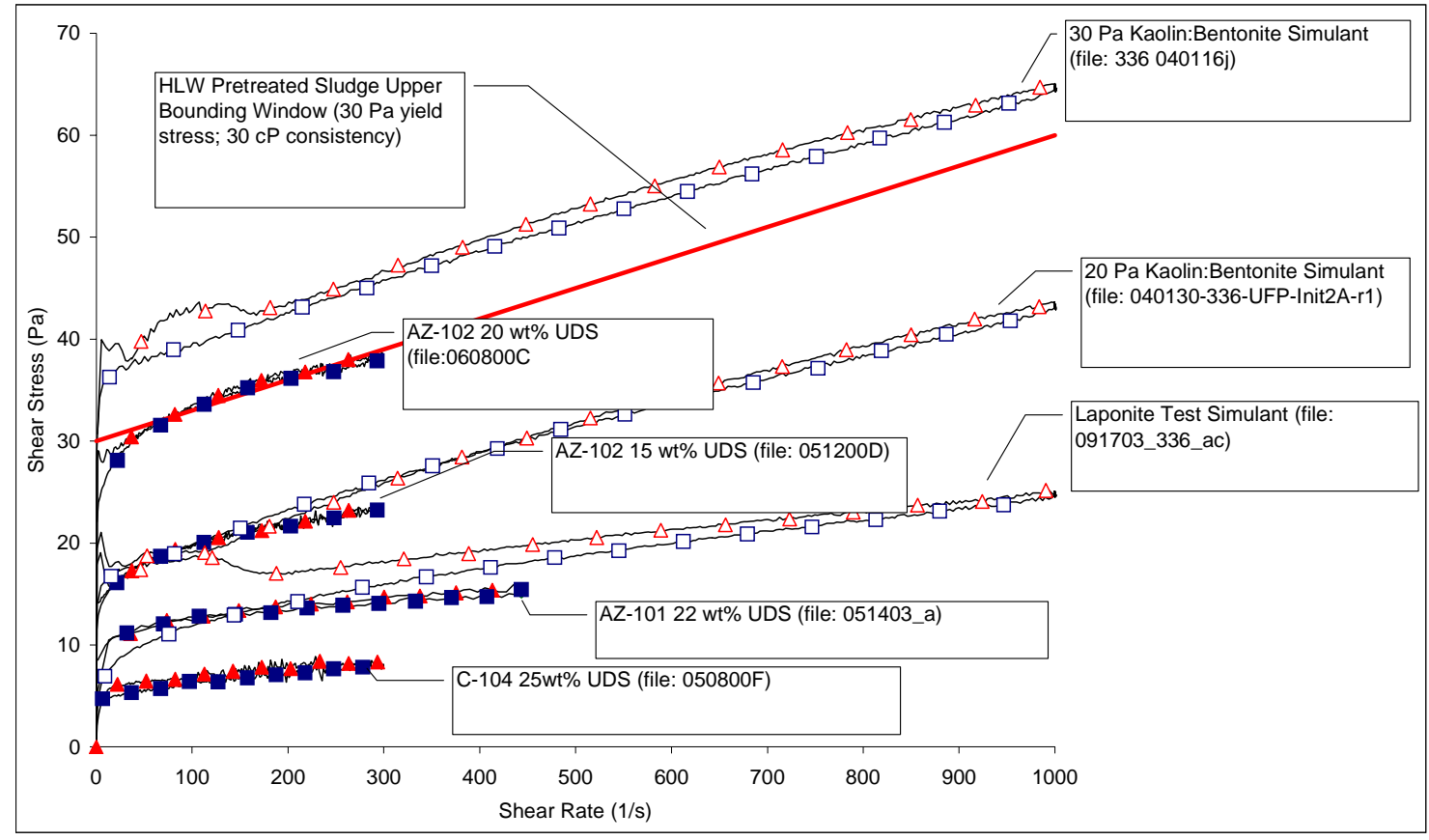

Figure 1-2. Flow Behavior Comparison of PJM Simulants and Actual HLW Pretreated Sludge 
In addition to not possessing the target rheological parameters desired for PJM testing, the Laponite composition also does not match other target values given in Table 1-5. The Laponite recipe calls for 1-2 wt\% Laponite RD in water where the actual waste is in the 15 to $25 \mathrm{wt} \%$ undissolved solids range. And the Laponite simulant consists of particles on the order of tens of nanometers, whereas the actual waste consists of particles in the tens of microns range. These differences may result in varying turbulent flow behavior in the PJM mixing cavern. For these reasons, a more representative particulate slurry was developed to enhance confidence in the PJM testing results. Unfortunately, this simulant is opaque.

The particulate simulant developed consists of a mixture of kaolin clay (EPK Feldspar Pulverized) and bentonite clay (WYO-Ben Big Horn CH-200) in water. To meet the WTP bounding parameters of Bingham plastic consistency of $30 \mathrm{cP}$ and yield stress $30 \mathrm{~Pa}$, a recipe was developed using these two clays. The recipe calls for a composite of $80 \%$ kaolin and $20 \%$ bentonite mixed with water to a loading of approximately $27 \mathrm{wt} \%$. Water is then added to the simulant to adjust the rheological parameters to other target values. Table 1-6 compares these simulants with actual waste at various solids loadings to target $30+$ and $20 \mathrm{~Pa}$ yield stress. A summary of the measured rheological parameters for significant CRV prototype tests and sparging tests is shown in Table 1-4. In addition, the bentonite/kaolin simulant shear strength behavior was observed to agree with Speers et al. (1987) correlation for drilling muds.

Table 1-6. Rheological Model Fits for CRV Prototype PJM Simulants at Ambient Temperature

\begin{tabular}{|c|c|c|c|}
\hline Test Group-Test Sequence & B-7 & E-2 & E-4 \\
\hline Date & 12/11/03 & 2/11/04 & 2/17/04 \\
\hline \multicolumn{4}{|l|}{ Bingham Plastic: } \\
\hline - Bingham yield stress $(\mathrm{Pa})$ & 17.5 & 32.9 & 32.8 \\
\hline k - Bingham consistency coefficient (cP) & 20.2 & 17.8 & 17.2 \\
\hline \multicolumn{4}{|l|}{ Herschel-Bulkley: } \\
\hline - yield stress $(\mathrm{Pa})$ & 15 & 28 & 26.4 \\
\hline k - Herschel-Bulkley consistency coeff. $\left(\mathrm{Pa} \cdot \mathrm{s}^{-\mathrm{b}}\right)$ & 0.274 & 0.35 & 0.522 \\
\hline b - Herschel-Bulkley power law exponent & 0.7026 & 0.615 & 0.544 \\
\hline
\end{tabular}

\subsection{DISCREPANCIES AND FOLLOW-ON TESTS}

While the Test Specification required tests with Laponite as simulant to visualize the gas holdup and release process, testing was done only with kaolin:bentonite simulant. This was necessary because the method of simulating gas generation used depended on catalyctic reaction between hydrogen peroxide and particles in the kaolin:bentonite simulant. No other discrepancies have been observed and no follow-on tests are planned. 
WSRC-TR-2004-00399, REVISION 0

SRNL-RPP-2004-00062, REVISION 0

\subsection{DISCUSSION}

\subsection{INTRODUCTION}

The Waste Treatment Plant (WTP) project plans to utilize Pulse Jet Mixer (PJM) technology for tank mixing applications requiring solids mixing, solids suspension, fluid blending, and release of hydrogen gas $\left(\mathrm{H}_{2}\right)$. PJM mixing tests have been initiated to provide design information on the operating parameters critical for the uniform movement (total mobilization) of non-Newtonian tank contents. While some mixing designs that rely on PJMs only have been demonstrated to be successful in mixing the vessel contents, due to impact on plant design and operating costs, hybrid-mixing designs utilizing PJMs and air spargers have also been investigated and shown to fully mobilize vessel contents. These mixing designs must also be shown to adequately release hydrogen generated during steady state operation and after loss-of-power effects to ensure plant safety.

BNI Process Engineering is utilizing a parametric model approach for providing design guidance for controllable release of flammable gas. Two key inputs to the model are gas holdup (how much gas is retained in the mixed waste during normal, continuous PJM operation) and gas release rate (how quickly gas is released upon PJM restart after a period of no mixing). Estimates of these two key parameters are being obtained from theoretical models and available data; however, these sources are limited. Scaled testing is required to validate models and obtain qualitative and quantitative data that will greatly strengthen the technical basis and defensibility of the parametric model inputs. This data will be used by Engineering to generate a defensible design basis for a selected PJM operating mode that will effectively assure the release of $\mathrm{H}_{2}$ from the waste.

Test Specification 24590-TSP-RT-03-011, Rev. 0 [1] provided requirements for performing GR\&R tests in the scaled Concentrate Receipt Vessel (CRV) mockup at Savannah River National Laboratory. These tests were to assess the volume fraction of gas retained in the simulant during continuous gas generation and steady state PJM operation (i.e., gas holdup tests), and the gas release characteristics (volume and rate) after the restart of mixing following a stoppage (i.e., gas release tests). The Test Plan is provided in Ref. [2]. This report specifically summarizes kaolin:bentonite clay simulant gas holdup and gas release tests completed in the CRV prototype vessel using near-final design configurations and operating conditions.

Testing beyond the scope of this task, i.e., other activities in the PJM area, includes benchscale development activities and experiments in PJM vessels covering a range of configurations and scales, all using non-Newtonian waste simulant. The basis for scale-up of the GR\&R results is not fully reviewed and could not be included in this document. 


\subsection{PRINCIPLE AND APPROACH}

To assess gas holdup and gas release in PJM tanks, gas bubbles are generated in situ in the simulant. The gas bubble generation technique is based on the decomposition of hydrogen peroxide $\left(\mathrm{H}_{2} \mathrm{O}_{2}\right)$ on catalytic surfaces according to the following reaction:

\section{Equation 2-1 $\quad \mathbf{2 H}_{2} \mathrm{O}_{2} \leftrightarrow 2 \mathrm{H}_{2} \mathrm{O}+\mathrm{O}_{2}$}

Once sufficient $\mathrm{H}_{2} \mathrm{O}_{2}$ has decomposed to supersaturate the simulant in $\mathrm{O}_{2}$, bubbles nucleate and existing bubbles grow. Further decomposition of $\mathrm{H}_{2} \mathrm{O}_{2}$ leads to additional bubble nucleation and/or bubble growth as $\mathrm{O}_{2}$ diffuses through the simulant to the bubbles. Generated gas will be retained or released depending on many factors, including the degree of mixing in the system, the retained gas volume fraction, the size of bubbles, and simulant rheology.

In gas holdup tests, $\mathrm{H}_{2} \mathrm{O}_{2}$ solution is added continuously for a period of time while the PJM system is operated normally to establish a constant gas generation rate. At steady state, the rate of gas generation equals the gas release rate (e.g., from bubbles migrating to the surface), and the steady-state gas volume fraction is termed the gas holdup. In gas release tests, the mixing system is shut down after an amount of $\mathrm{H}_{2} \mathrm{O}_{2}$ solution is added to allow gas bubbles to be retained in the quiescent simulant. The release of gas upon restart of the mixing system is tracked to assess gas release volumes and rates.

The primary data obtained in gas holdup and gas release tests are measurements of the simulant surface level as a function of time. Through independently established correlations, the level measurements are used to calculate retained gas volume and gas volume fractions. The gas volume fraction $\alpha$ referenced to the initial simulant volume is defined as

Equation 2-2 $\quad \alpha=\frac{V_{\text {gas }}}{V_{o}}=\frac{V_{\text {gas }}}{V_{\text {sim }}+V_{\text {sol }}}$

where $V_{\text {gas }}$ is the volume of retained gas (e.g., $\mathrm{O}_{2}$ bubbles), and the total initial slurry volume $V_{o}$ includes the bubble-free simulant volume $V_{\text {sim }}$ and the volume of $\mathrm{H}_{2} \mathrm{O}_{2}$ solution $V_{\text {sol }}$. In many cases $V_{\text {sol }}$ is negligible compared with the large volume of gas-free simulant. However, in gas holdup experiments where $\mathrm{H}_{2} \mathrm{O}_{2}$ solution is added continuously for an extended period of time, a correction is made for the added solution volume. 
According to the expected reaction stoichiometry (shown in Equation 2-1), two moles of $\mathrm{H}_{2} \mathrm{O}_{2}$ decompose to produce 1 mole of $\mathrm{O}_{2}$ and 2 moles of $\mathrm{H}_{2} \mathrm{O}$. Using this relationship, the nominal $\mathrm{H}_{2} \mathrm{O}_{2}$ solution concentration ( $30 \mathrm{wt} \%$ ), and ideal gas law considerations, the equivalent volumetric rate of $\mathrm{O}_{2}$ gas generation can be determined for a given rate of $\mathrm{H}_{2} \mathrm{O}_{2}$ decomposition. Assuming instantaneous $\mathrm{H}_{2} \mathrm{O}_{2}$ decomposition or a steady process where a steady-state concentration of $\mathrm{H}_{2} \mathrm{O}_{2}$ is established in the slurry, $\mathrm{O}_{2}$ gas is generated at a rate equivalent to $\mathrm{H}_{2} \mathrm{O}_{2}$ introduction. The latter is assumed to occur in gas holdup experiments, and reported steady-state volumetric gas generation rates (at $22^{\circ} \mathrm{C}$ and $1 \mathrm{~atm}$ ) are calculated from measured $\mathrm{H}_{2} \mathrm{O}_{2}$ injection rates. Normalizing the gas volume generation rate by the volume of simulant in the vessel gives the specific volumetric gas generation rate (volume of $\mathrm{O}_{2}$ gas/volume of simulant/time).

\subsection{QA PROGRAM}

This work was conducted in accordance with the RPP-WTP QA requirements specified for work conducted by SRNL as identified in DOE IWO MOSRLE60. All instrumentation used in this test program was calibrated according to 1Q Manual, Sec. 12-1, "Control of Measuring and Test Equipment."

\subsubsection{CRV Vessel and PJM Configuration}

This section describes the scaled CRV vessel and the final PJM configurations. The 168-inch-diameter, full-scale CRV tank was represented by a 40.125 -inch-ID clear acrylic vessel. The geometric scale factor was $\sim 4.0$. The scaled CRV prototypic test vessel was $76 \pm 1$ inches tall with a $\sim 2: 1$ elliptical dish head made out of stainless steel. The final, selected PJM arrangement is the so called "Chandelier" arrangement, Figure 2-1. Here, the charge vessels are positioned along the vessel wall along radial centerlines between PJMs. This is to ensure a flow distribution as close to symmetrical as possible.

All of the PJMs for the final, selected CRV prototype of the "Chandelier" arrangement were constructed from 8-inch-diameter (8.329-inch ID) schedule 10 stainless steel pipes with the end connected to an approximately $60^{\circ}$ angle cone truncated to a 1.5-inch-diameter collar to which the nozzles were fitted. Figure 2-2 is a drawing of the PJM assembly. The cylindrical section of the PJMs was $37 \pm 1$ inches tall; this corresponds to a PJM height scale factor of $\sim 4.32$. The difference between the CRV tank dimension scale factor and the pulse tube dimension scale factor was due to the need to use standard pipe sizes for procurement expediency. However, the volume expelled from the PJMs was consistent with the CRV vessel scale factor of $\sim 4.0$.

The center PJM nozzle (Figure 2-3) was constructed from a drilled stainless steel pipe cap attached to a $60^{\circ}$ cone and was pointed straight down toward the center of the tank bottom and raised approximately 2 inches off the bottom. Two types of perimeter PJM nozzles were used. One, (Figure 2-4 - 1.05-inch ID shown) was angled $45^{\circ}$ (using welded pipe sections) from the vertical; and the other (Figure 2-5) was angled $135^{\circ}$ from the vertical. Both were directed radially outward from the tank center and raised approximately 2 inches off the tank floor. 
WSRC-TR-2004-00399, REVISION 0

SRNL-RPP-2004-00062, REVISION 0

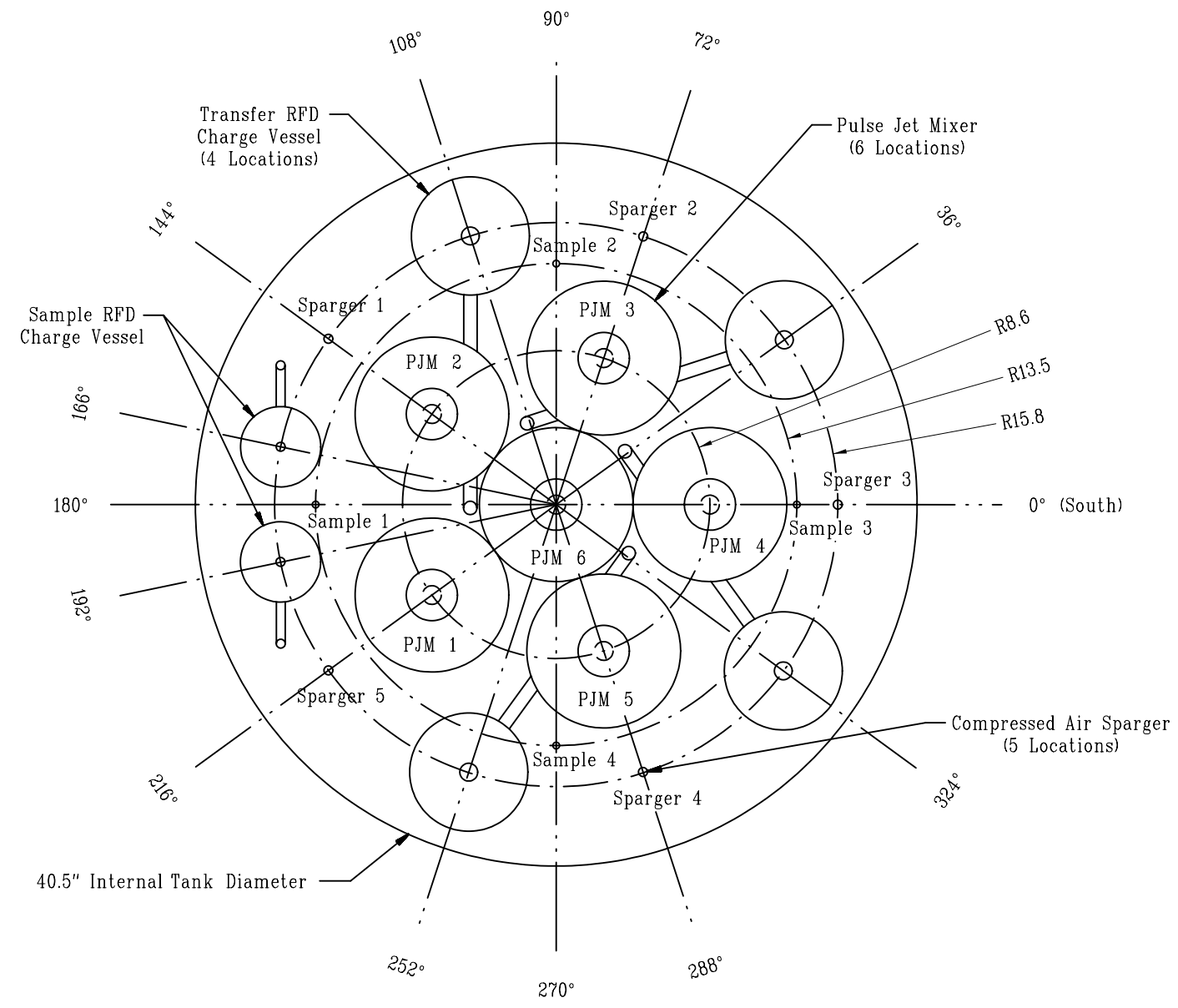

Figure 2-1. Top View of the CRV Prototypic Test Stand Showing Nominal Dimensions 
WSRC-TR-2004-00399, REVISION 0

SRNL-RPP-2004-00062, REVISION 0

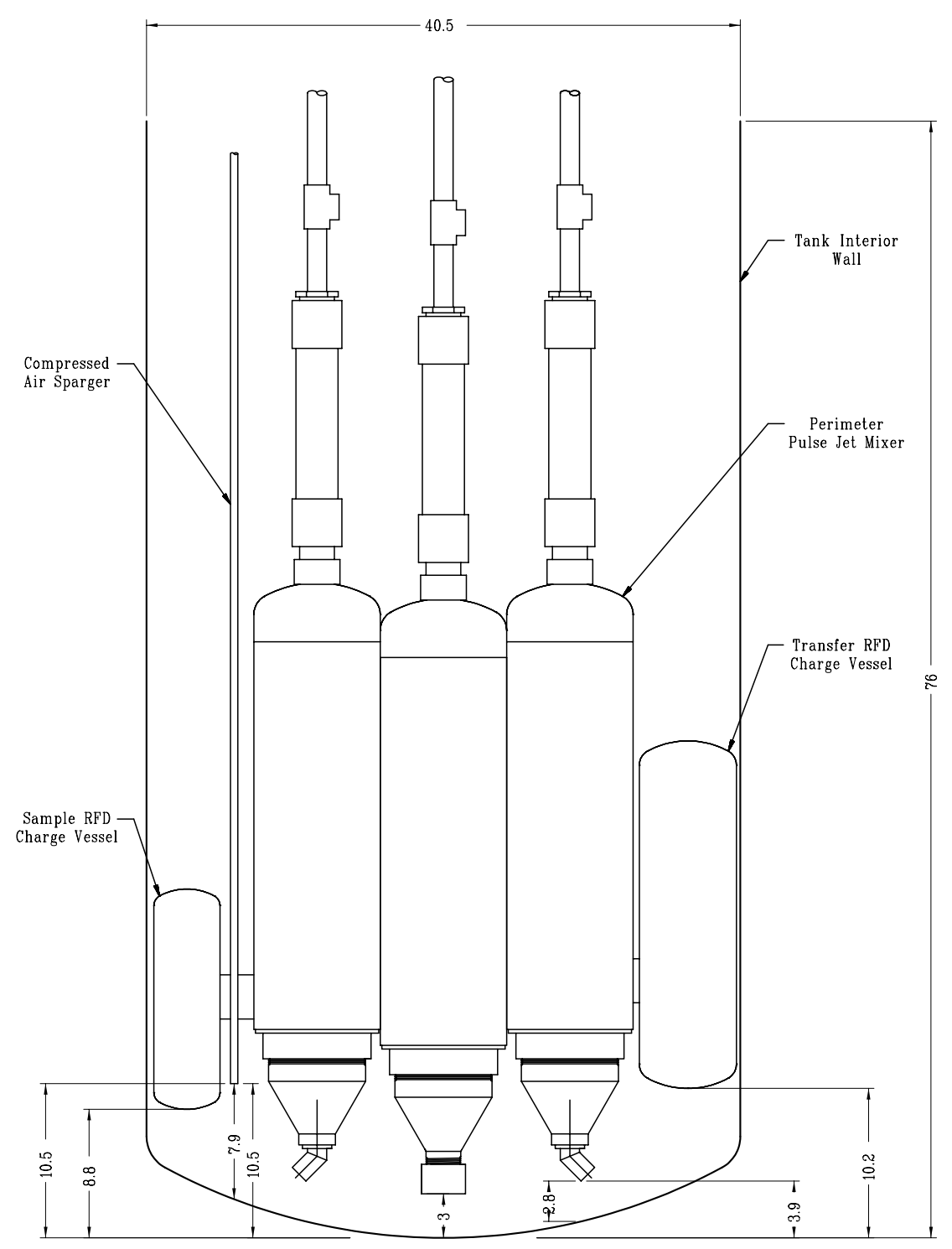

Figure 2-2. Plan View of the CRV Test Stand Showing Nominal Dimensions 
WSRC-TR-2004-00399, REVISION 0

SRNL-RPP-2004-00062, REVISION 0

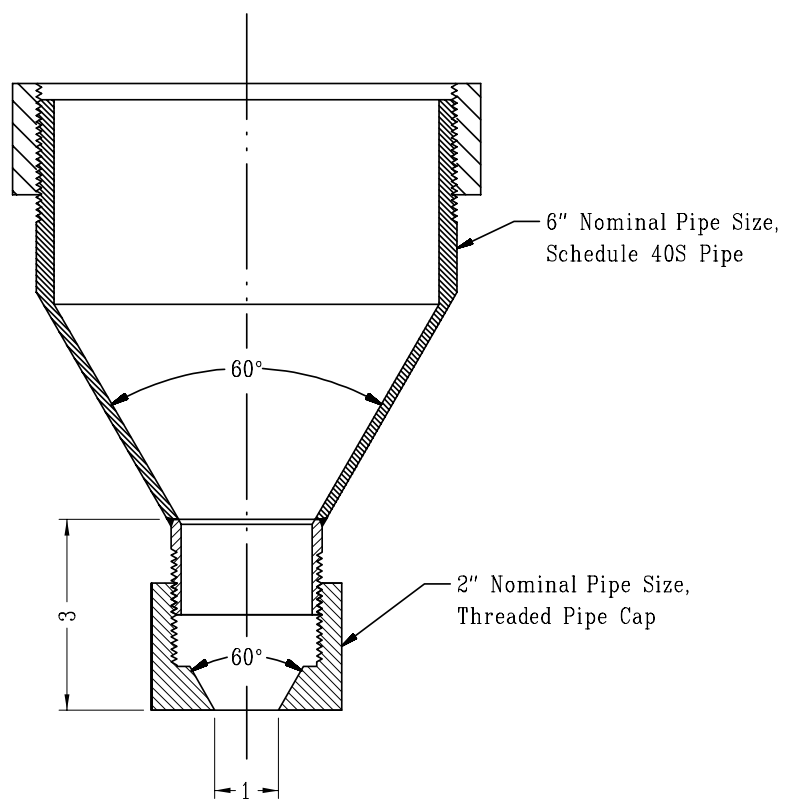

Figure 2-3. Center Nozzle Showing Nominal Dimensions for 1-inch Nozzle

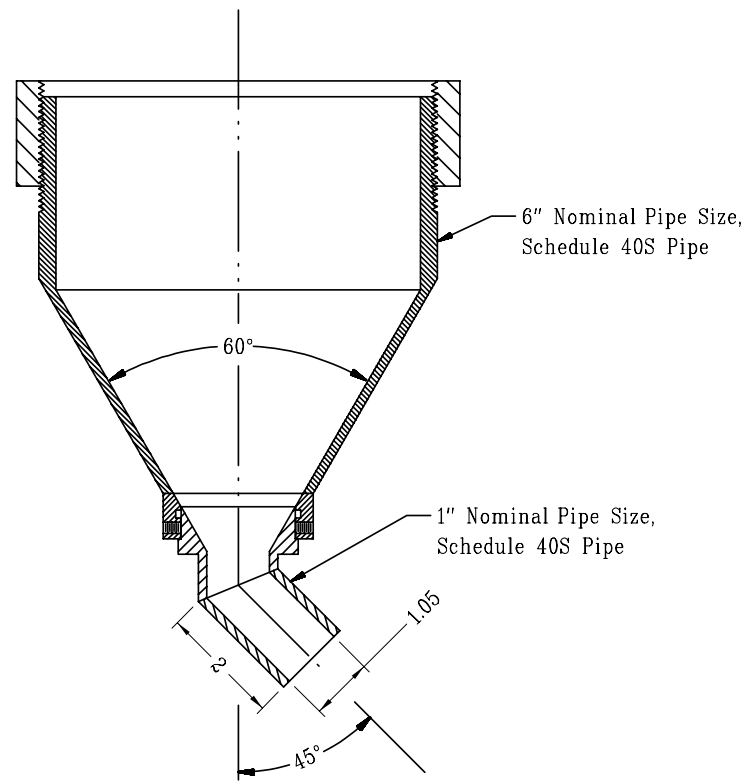

Figure 2-4. $45^{\circ}$ Nozzle; Showing Nominal Dimensions for I-inch Nozzle 


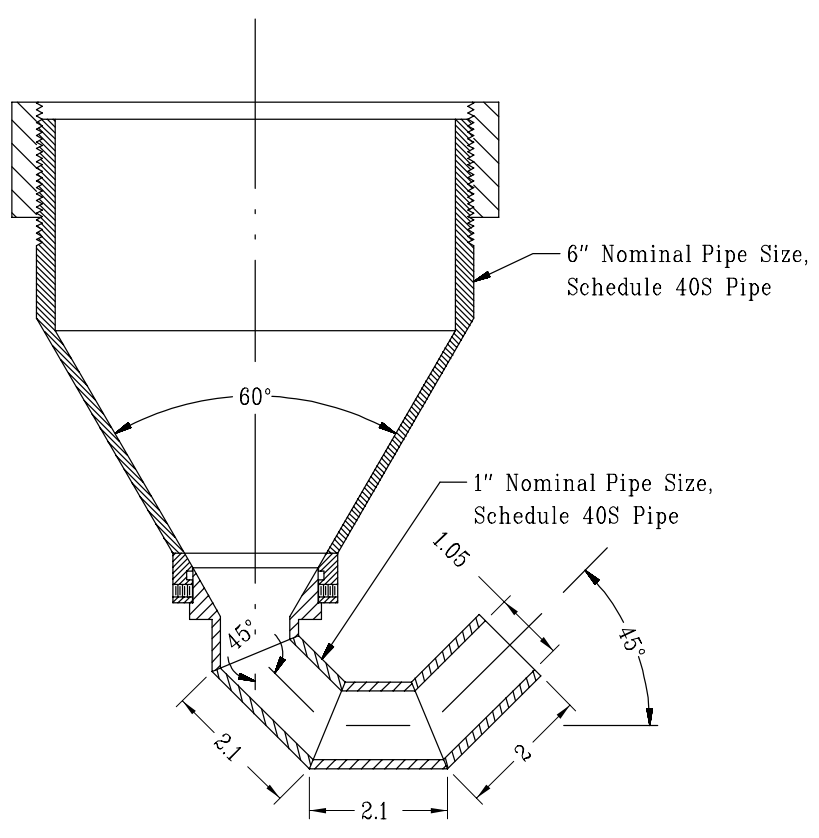

Figure 2-5. $135^{\circ}$ Nozzle Showing Nominal Dimensions for 1-inch Nozzle

Only two combinations of nozzles were used. The first, which will be called the Down Nozzle Configuration, consists of five $45^{\circ}$ downward facing nozzles and one center down nozzle. The second, which will be called the Up/Down Nozzle Configuration, consists of three $135^{\circ}$ Nozzles at PJMs 1,2 , and 4 , two $45^{\circ}$ down nozzles, and one center down nozzle.

Tests using spargers were performed using an array of 5 spargers at a pitch circle of 31.6 in. The spargers were located approximately at the center of the open regions between the charge vessels, as shown in Figure 2-6. All sparger tubes were made from 0.5-inch-OD ( 0.37 inch ID) stainless steel tubing, and the lower ends of the sparger tubes were approximately 10.5 inches above the bottom of the tank as measured from the tank bottom. The sparger flow rates were individually controlled with throttle valves and measured with rotameters for equal flows. The total air flow was measured with a Kurz mass air flowmeter and recorded on the data acquisition system. 


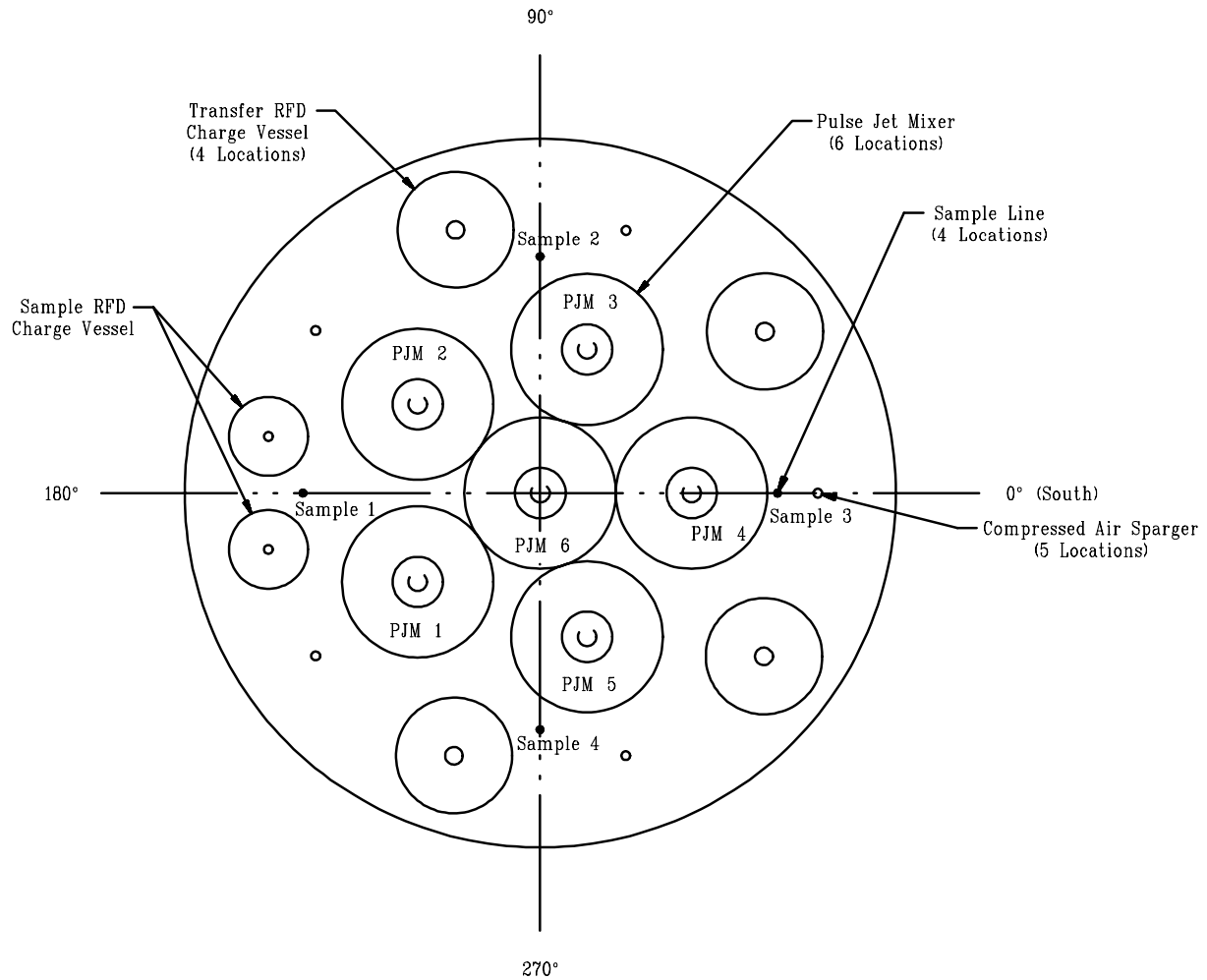

Figure 2-6. Sparger and Sample Line Locations in Final "Chandelier" Arrangement

\subsubsection{System Operation and Data Acquisition System}

Unlike conventional PJMs, whose operation is regulated by JPPs driven by compressed air, the prototype test systems used a series of solenoid valves and a combination of an air compressor and a vacuum pump to simulate the drive and suction phases of PJM operation. These operations were controlled through a control logic program using Labview software that turns the appropriate solenoid valves on and off at specified time intervals. The duration of each phase, the applied pressure, and the vacuum are all variables that can be independently varied to simulate the operation of the PJMs. The PJMs were operated at a specific average nozzle velocity $\left(\overline{\mathrm{u}}_{\text {disch }}\right)$, which is defined as

$$
\text { Equation 2-3 } \quad \bar{u}_{\text {disch }}=\frac{\Delta H}{\Delta t} * A R
$$

where $\Delta H$ is the length of the PJM stroke, $\Delta t$ is the time for achieving the stroke, and $A R$ is the area ratio of the PJM to the nozzle. 
The drive distance was based on volume scaling to the plant, given the linearly scaled PJM diameter. The drive distance was approximately 27 -inches for Test B-7 and E-4. When the 8-inch PJM was used to simulate the 6-inch PJM as in Test E-2, the drive distance was reduced to 16-inches. During the drive portion of the cycle, the drive time was set so that the nominal velocity was achieved, knowing the initial and final simulant levels inside the PJM. The cycle time was controlled to be one over the scale factor of the plant cycle time and includes times for venting and quiescent periods.

During each mixing test, several variables such as PJM liquid levels, pressures, tank temperatures, air supply pressure, and total sparger air flow rate were monitored continuously and recorded digitally on a computer. The liquid/slurry level inside each of the PJMs was measured using Drexelbook capacitance level probes and transmitters. The level probes were calibrated against a tape measure on the side of the tank whenever there was a change of simulant (slurry yield stress changed). Compressor and vacuum supply pressures and the pressure inside each PJM were monitored using flush-diaphragm Endress + Hauser ceramic pressure transducers, installed at a pipe Tee fitting near the top of the PJM. Data from these sensors were recorded on a laboratory computer, running Labview software at sampling times of approximately 0.1 seconds.

All instrumentation used in this experiment were calibrated and conformed to QA procedures for Measuring and Test Equipment, as required by the QA program in the Task Plan.

\subsubsection{Tank Level Measurement}

Measurement of the tank level by means of a DISTO PRO laser sensor was the primary means of determining the gas fraction. The laser sensor was positioned above the tank and the laser light was directed at the middle of a annular sector between the PJM and the tank wall. During quiescent periods (no PJM or sparger operation), the sensor reading represented the average tank level. However, during PJM operation, the minimum level (suction phase) was recorded to track the gas release rate. The pulsing was also stopped at regular intervals to establish a quiescent tank level. The laser sensor readings were checked against readings taken with measuring tapes.

\subsection{TEST METHODS}

\subsubsection{Gas Holdup Tests}

Two types of holdup tests were run. In the overnight growth or batch injection test, a given mass of $30 \mathrm{wt} \%$ hydrogen peroxide was injected at a high rate through a sampling line near the bottom of the tank, while the PJMs and spargers were operating, and after completion of injection, the PJMs and spargers continued for 15 minutes to ensure full mixing, and then stopped. The tank level was then monitored overnight. In the steady state gas generation rate test, a given hydrogen peroxide injection rate is maintained for approximately 100 minutes to determine a steady state gas fraction. The injection was stopped and the PJMs and spargers continued to operate for another 100 minutes and then stopped. The gas fraction buildup was then monitored. Table 2-1 provides the amount and injection rates of hydrogen peroxide for the three CRV mixing test configurations. 
WSRC-TR-2004-00399, REVISION 0

SRNL-RPP-2004-00062, REVISION 0

Table 2-1. Hydrogen Peroxide Injection Rates for Gas Holdup Tests

\begin{tabular}{|c|c|c|c|c|c|c|c|c|}
\hline \multirow[b]{2}{*}{$\begin{array}{l}\text { Test } \\
\text { Group }\end{array}$} & \multirow[b]{2}{*}{$\begin{array}{c}\text { Test } \\
\text { Sequence }\end{array}$} & \multirow[b]{2}{*}{ Test type } & \multicolumn{3}{|c|}{$\begin{array}{c}\text { Total } \mathrm{H}_{2} \mathrm{O}_{2} \text { mass } \\
\text { injected, gm }\end{array}$} & \multicolumn{3}{|c|}{ Injection rate, $\mathrm{ml} / \mathrm{min}$} \\
\hline & & & $\begin{array}{c}\text { Batch } \\
\text { inj. }\end{array}$ & $\begin{array}{l}\text { Slow } \\
\text { rate }\end{array}$ & $\begin{array}{l}\text { Fast } \\
\text { rate }\end{array}$ & $\begin{array}{c}\text { Batch } \\
\text { inj. }\end{array}$ & $\begin{array}{l}\text { Slow } \\
\text { rate }\end{array}$ & Fast rate \\
\hline $\mathrm{B}$ & 7 & Gas holdup & 1323 & 1365 & 2877 & 220 & 8.4 & 23 \\
\hline $\mathrm{E}$ & 2 & Gas holdup & 663 & $\mathrm{~N} / \mathrm{A}$ & 2180 & 220 & $\bar{N} / \mathrm{A}$ & 22.8 \\
\hline $\mathrm{E}$ & 4 & Gas holdup & 663 & $\mathrm{~N} / \mathrm{A}$ & 2000 & 220 & $\mathrm{~N} / \mathrm{A}$ & 22.8 \\
\hline
\end{tabular}

\subsubsection{Gas Release Tests}

After the holdup tests reached a steady state gas fraction, the mixing systems were started and stopped to determine the quiescent tank level, until the initial gas free tank level was reached.

\subsection{TEST RESULTS}

\subsubsection{Gas Retention Under Various $\mathrm{H}_{2} \mathrm{O}_{2}$ Injection Rates}

This section illustrates the rate of increase of gas holdup and the maximum holdup attained in the event that the CRV PJMs and spargers are out of operation for an extended period of time. In the overnight growth test, a given mass of $\mathrm{H}_{2} \mathrm{O}_{2}$ was injected into the simulant at a high rate, typically $220 \mathrm{ml} / \mathrm{min}$, mixed well with PJMs and spargers, and then the gas is allowed to expand overnight. This represents the upper end of the gas retention since no gas was released during the batch injection. The results of tests on the three CRV mixing configurations are as follows:

In Test B-7, with PJMs only configuration (1.5" nozzles, upward/downward facing nozzles), $1327 \mathrm{gm}$ of 30 wt. $\% \mathrm{H}_{2} \mathrm{O}_{2}$ solution was injected into the simulant at a rate of $220 \mathrm{ml} / \mathrm{min}$, with the PJMs running for 15 minutes before they were stopped. The rate of increase in gas fraction is shown in Figure 2-7. A maximum gas fraction of $16.3 \%$ was reached in about 3 hours.

In Test E-2, with a hybrid-mixing system (1" downward facing nozzles, 3 spargers @ $1.9 \mathrm{scfm}$ ea.), $663 \mathrm{gms}$ of $\mathrm{H}_{2} \mathrm{O}_{2}$ solution was used in the batch mode. A maximum gas fraction of $5.5 \%$ was reached in about 60 minutes.

In Test E-4, also with a hybrid mixing system (1" upward/downward facing nozzles, 5 spargers @ $1.8 \mathrm{scfm}$ ea.), the same amount of $\mathrm{H}_{2} \mathrm{O}_{2}$ solution was injected as in Test E-2. A closely similar gas fraction (4.9\%) was reached in Test E-4 in 50 minutes. 


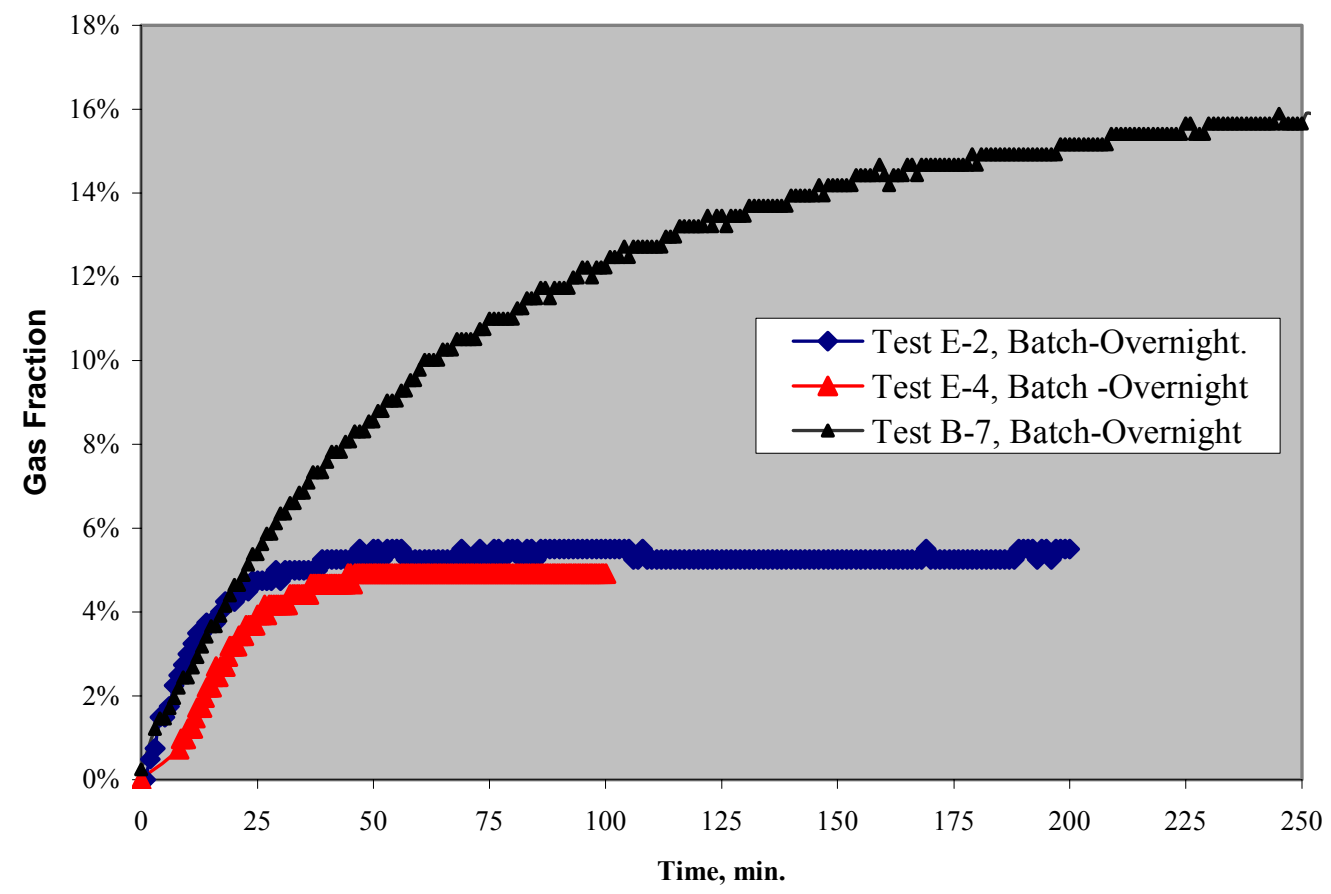

Figure 2-7. Gas Fraction as a Function of Time after Batch Injection of $\mathrm{H}_{2} \mathrm{O}_{2}$ in Three Gas Holdup Tests in the CRV

\subsubsection{Gas Holdup in Normal Operations}

This section demonstrates that gas is released regularly and controllably in normal operation of the CRV prototype system, resulting in relatively low gas holdup.

In Test B-7, two rates of $\mathrm{H}_{2} \mathrm{O}_{2}$ injection were used. In the slow injection test, $1365 \mathrm{gm}$ of $30 \mathrm{wt} \% \mathrm{H}_{2} \mathrm{O}_{2}$ was injected at a rate of $8 \mathrm{ml} / \mathrm{min}$, while for the fast injection test, 2860 gms of $\mathrm{H}_{2} \mathrm{O}_{2}$ solution was injected at twice the rate of the slow rate (or $16 \mathrm{ml} / \mathrm{min}$ ). For both slow and fast injection tests, the PJMs were operated continuously during the approximately 100 minutes of injection and 100 minutes after the end of the injection. Figure 2-8 shows that during operation of the $\mathrm{PJM} /$ spargers, the steady state gas fraction did not exceed $0.5 \%$, which was reached in $100 \mathrm{~min}$. or a gas generation rate of $0.005 \% / \mathrm{min}$. After the PJMs and spargers were turned off, the gas fraction started to rise again. The rate of rise of the gas fraction was higher for the slow injection test (17.6\% in $4.6 \mathrm{hrs)}$ than for fast injection test $23.6 \%$ in $13 \mathrm{hrs}$ ). This was probably due to the kinetics of gas generation in the particulate simulant. However it is the total amount of $\mathrm{H}_{2} \mathrm{O}_{2}$ injected which determines the maximum gas holdup value. 
Figure 2-9 plots the measured gas volume fraction as a function of time during and after a gas holdup test in the CRV scaled prototype with a hybrid-mixing system (Test E-2). At elapsed time 0 , a hydrogen peroxide addition rate $(22.5 \mathrm{ml} / \mathrm{min}$ of $30 \mathrm{wt} \%$ hydrogen peroxide) was established to provide an effective $\mathrm{O}_{2}$ gas generation rate of $0.028 \mathrm{vol} \% / \mathrm{min}$ (normalized to atmospheric pressure and $22^{\circ} \mathrm{C}$ ) and a maximum steady state gas fraction of $2 \%$. The specific gas generation rates used in the prototype experiments exceed the expected maximum actual waste gas generation rates (e.g., $2-4 \mathrm{vol} \% /$ day) by a factor of $\sim 10$ or more.

A steady-state gas fraction of $\sim 2 \mathrm{vol} \%$ was attained after $\sim 70$ minutes. After an elapsed period of 103 minutes, the PJMs and spargers were turned off. Figure 2-9 shows the gas holdup increasing to $7.5 \%$ after about 27 minutes.

In Test E-4, a continuous injection of $27 \mathrm{ml} / \mathrm{min}$ of $30 \mathrm{wt} \%$ solution was used with the PJMs and spargers on for 108 minutes (Figure 2-10). A rate of gas fraction increase of $0.02 \% / \mathrm{min}$. was observed with a maximum gas fraction of $1 \%$. After the PJMs and spargers were turned off, a maximum gas fraction of $5.9 \%$ was reached.

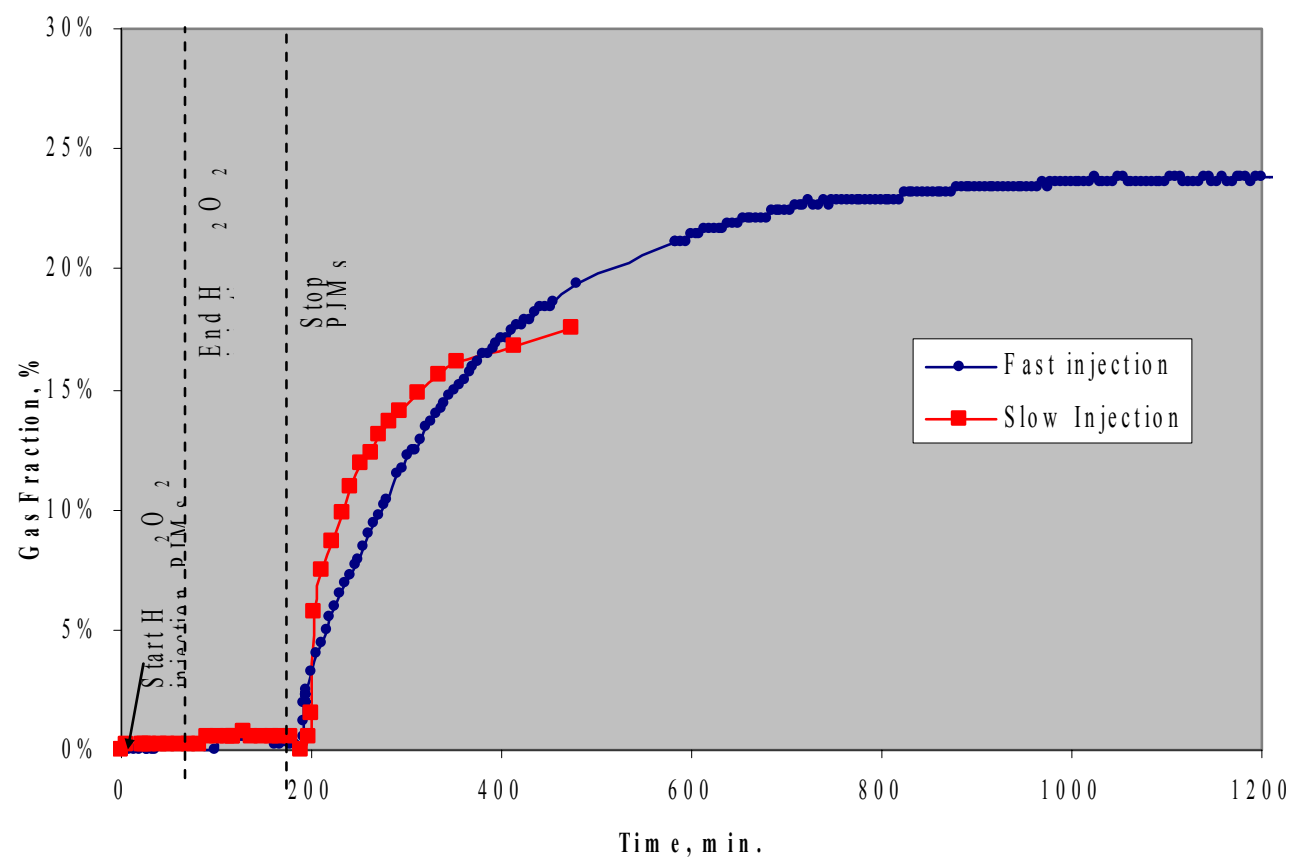

Figure 2-8. Gas Fraction as a Function of Time During and After Continuous $\mathrm{H}_{2} \mathrm{O}_{2}$ Injection in the CRV Prototype (Test B-7).

Events are marked on the plot by vertical lines. 
WSRC-TR-2004-00399, REVISION 0

SRNL-RPP-2004-00062, REVISION 0

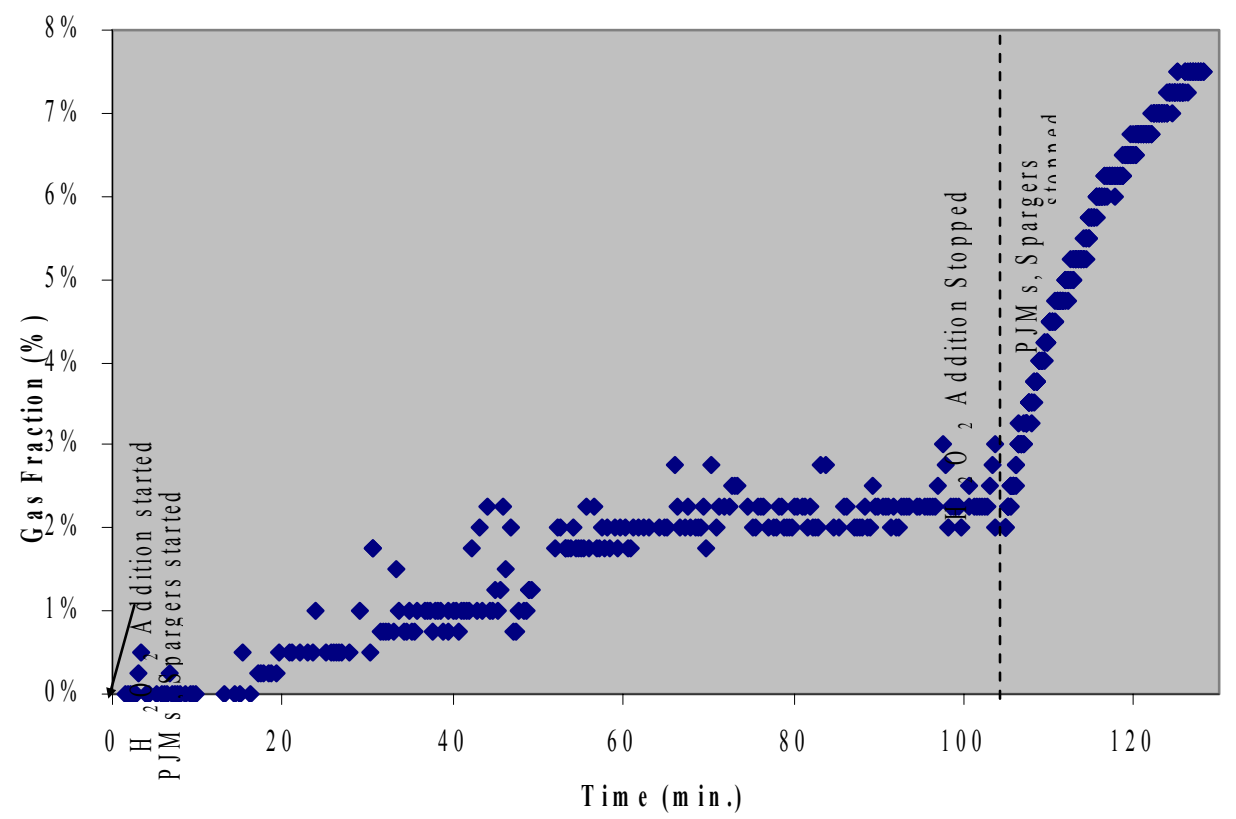

Figure 2-9. Gas Fraction as a Function of Time During and After Continuous $\mathrm{H}_{2} \mathrm{O}_{2}$ Injection in the CRV Prototype (Test E-2).

Events are marked on the plot by vertical lines.

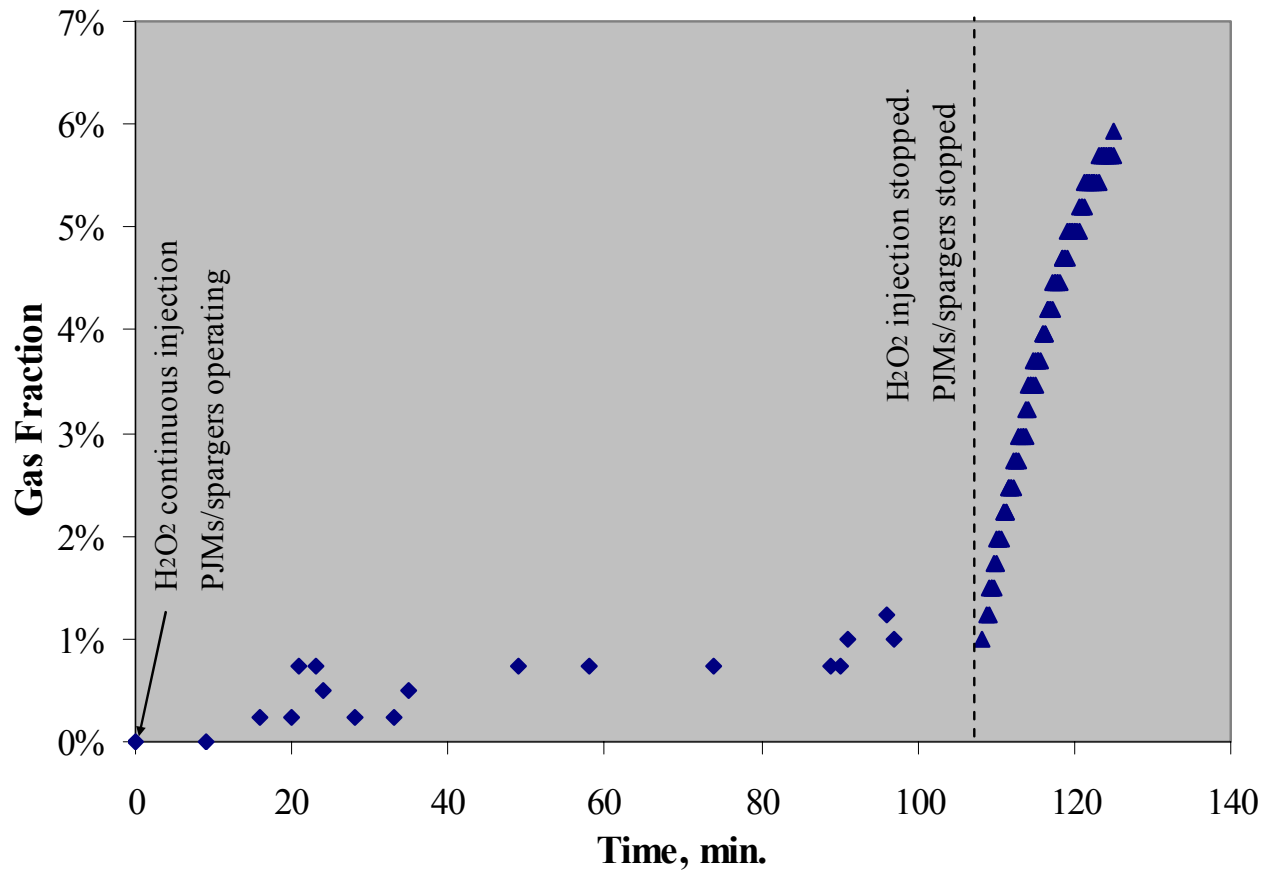

Figure 2-10. Gas Fraction as a Function of Time During and After a Gas Holdup Test in the CRV Prototype (Test E-4).

Events are marked on the plot by vertical lines. 
WSRC-TR-2004-00399, REVISION 0

SRNL-RPP-2004-00062, REVISION 0

Table 2-2 provides the experimental gas release and holdup values in the CRV test stand under normal operating conditions.

\section{Table 2-2. Experimental Gas Release and Holdup in the CRV Test Stand Under Normal Operating Conditions}

\begin{tabular}{|c|c|c|}
\hline Configuration & $\begin{array}{c}\text { Experimental Gas } \\
\text { Generation Rate } \\
\text { (vol\%/min) }\end{array}$ & $\begin{array}{c}\text { Measured Gas Holdup } \\
\text { (vol\%) }\end{array}$ \\
\hline $\begin{array}{c}\text { Test B-7: 6 PJMs with } \\
\text { three 1.5" upward nozzles and } \\
\text { three 1" downward nozzles }\end{array}$ & 0.005 & 0.5 \\
\hline $\begin{array}{c}\text { Test E-2: 6 PJMs @ 12 m/s } \\
\text { nozzle vel., downward nozzles, } \\
\text { 3 spargers at 1.9 scfm ea. }\end{array}$ & 0.028 & 2.0 \\
\hline $\begin{array}{c}\text { Test E-4: 6 PJMs with } \\
\text { three 1" upward nozzles and } \\
\text { three 1" downward nozzles, } \\
5 \text { spargers at 1.8 scfm ea. }\end{array}$ & 0.02 & 1 \\
\hline
\end{tabular}

\subsubsection{Gas Release after Mixing System Restart}

During a plant shutdown in which the air supply to PJMs and spargers is interrupted, generated gas is expected to accumulate in the quiescent waste. In the extreme, all gas generated during the outage will be retained in the waste slurry. Upon restart of the mixing apparatus, accumulated gas is likely to be released. The release rate is dependent on many factors including waste rheology and mixing energy. Examples of gas release from gelled clay resulting from the restart of PJMs and spargers in the CRV prototype are provided.

In Figure 2-11, gas accumulated in Figure 2-7 (overnight growth test), Test B-7, of up to $18 \%$ was released by operating the PJMs. The tank level was tracked by measuring the lowest tank level during the suction phase of the PJM cycle. After 10 cycles, the PJMs were stopped and the tank level stabilized at a value of $2.7 \%$. After another 20 cycles, the PJMs were stopped and the gas fraction reached $1.5 \%$.

In Figure 2-12, the gas fraction at the end of the overnight growth holdup test, Test E-2 (Figure 2-8) of 5.5\% decreased to $0.7 \%$ after 10 cycles and then to $0.25 \%$ after 20 cycles of PJM and sparger operation. In Figure 2-13, the gas accumulated in overnight growth Test E-4 (Figure 2-8) of 4.7\% was totally released after 20 cycles ( $8 \mathrm{~min}$.) of PJM and sparger operation. 


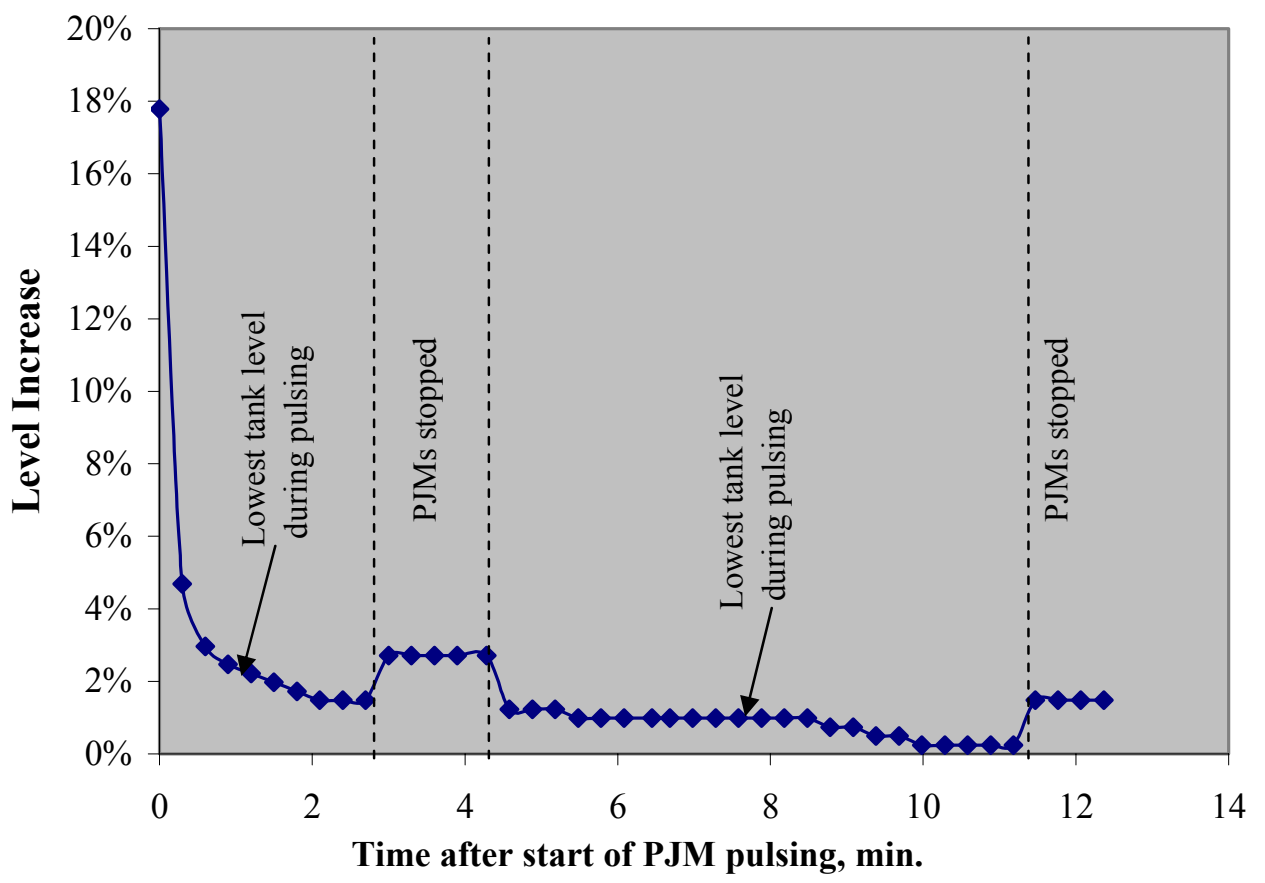

Figure 2-11. Gas Release from Gelled Clay in the CRV Prototype after Gas Holdup in Figure 2-7 (Test B-7, six PJMs, 3 upwards 1.5" nozzles and 3 downwards 1.5 " nozzles)

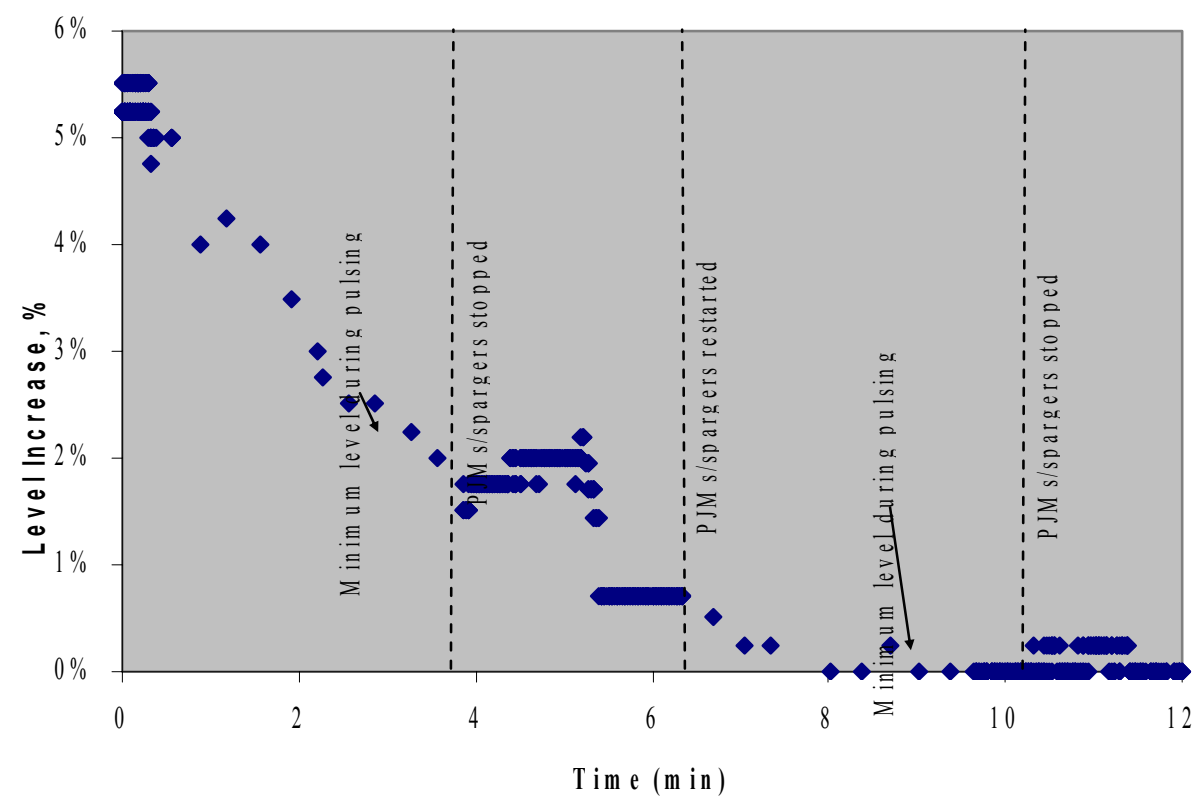

Figure 2-12. Gas Release from Gelled Clay in the CRV Prototype after Gas Holdup in Figure 2-7 (Test E-2, six PJMs, 1" downward nozzles+ 3 spargers @ $1.9 \mathrm{scfm}$ ea.) 


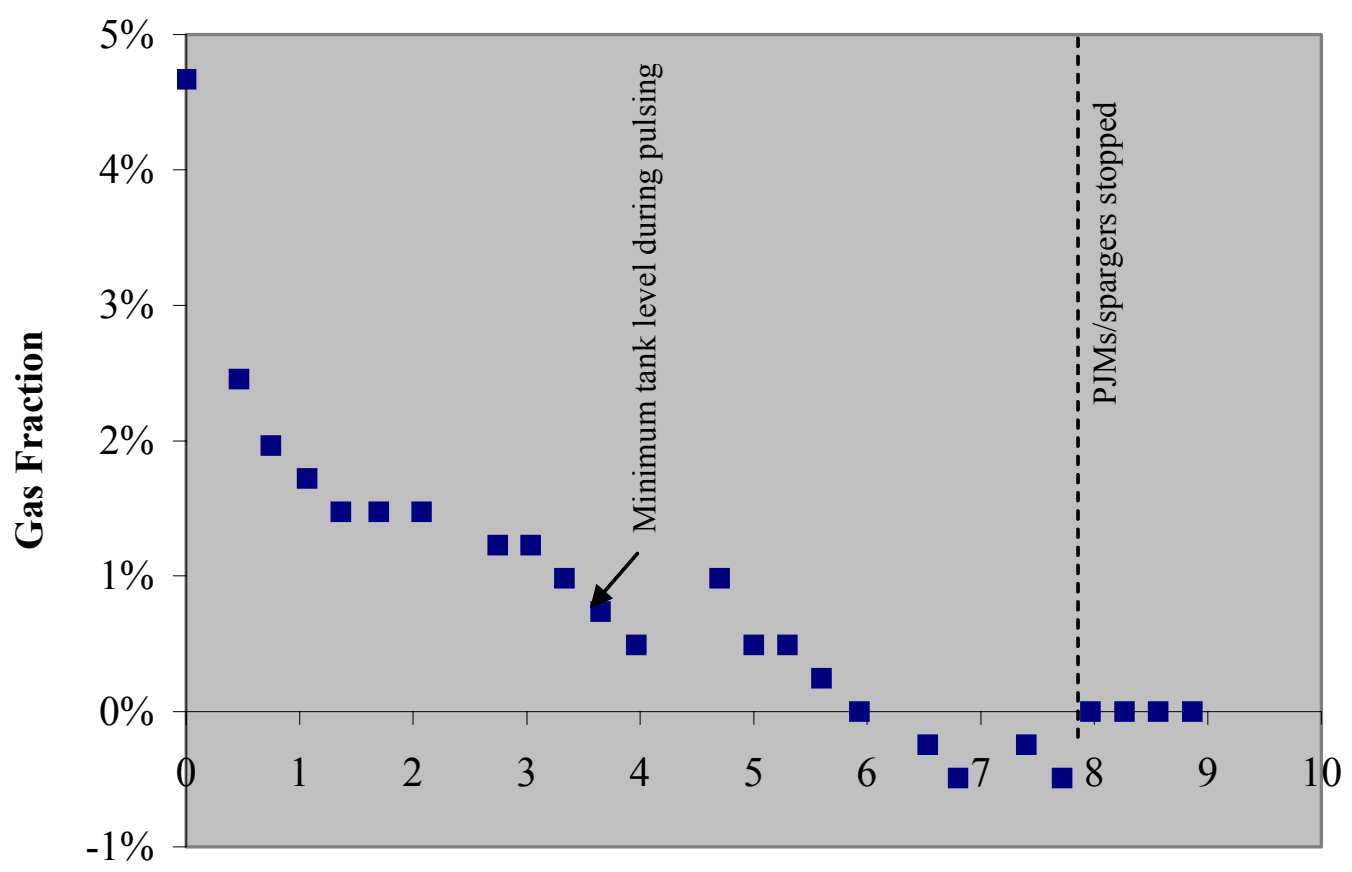

Time, min.

Figure 2-13. Gas Release from Gelled Clay in the CRV Prototype after Gas Holdup in Figure 2-7 (Test E-4, six PJMs, 3 upwards 1.5" nozzles and 3 downwards 1.5" nozzles)

In Figure 2-14, starting at an initial gas fraction ( $\sim .5 \mathrm{vol} \%$ after the continuous injection test, Figure 2-9) with the PJMs and spargers operating, gas was released to a retained gas volume fraction of $\sim 1.25 \mathrm{vol} \%$ in $22 \mathrm{~min}$, decaying with time. Then the PJMs and spargers were turned off. The gas fraction again increased to a steady state value of $1.5 \%$ after 30 minutes. The spargers only were turned on, which did not completely release the gas, allowing a residual holdup of $1 \%$. When the PJMs were turned on, all of the gas was released.

In Figure 2-15, starting at an initial gas fraction $(\sim 5 \mathrm{vol} \%$ from continuous injection test, Figure 2-10) with the PJMs and spargers operating, gas was released to a retained gas volume fraction of $\sim 0.25 \mathrm{vol} \%$ in $22 \mathrm{~min}$. Then the PJMs and spargers were turned off. The gas fraction again increased to a steady state value of $0.5 \%$ after 30 minutes. The spargers only were turned on, which completely released the gas.

In comparing Test E-2 and Test E-4 (Figure 2-14 and Figure 2-15, respectively.), it is interesting to note that after the initial release with both the PJMs and spargers on and the holdup attained a residual value, not all the gas was released in Test E-2, but all the gas was released in Test E-4 with the spargers operating only. This is evidently due to a larger air volumetric flow in Test E-4 (5 spargers, 9 scfm) than in Test E-2 (3 spargers, $6 \mathrm{scfm})$. 


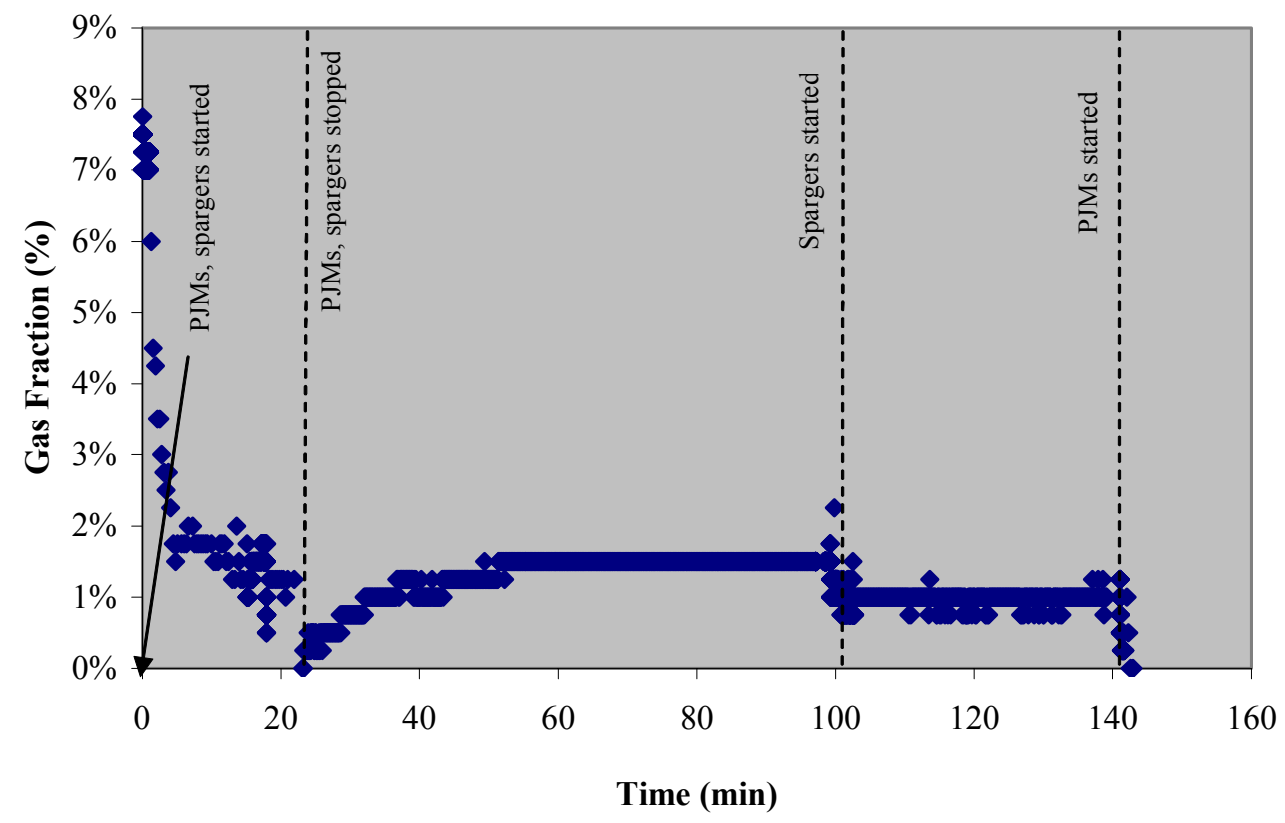

Figure 2-14. Gas Release from Gelled Clay in the CRV Prototype after Gas Holdup in Figure 2-9 (Test E-2, six PJMs + three spargers at $1.9 \mathrm{scfm}$ ea)

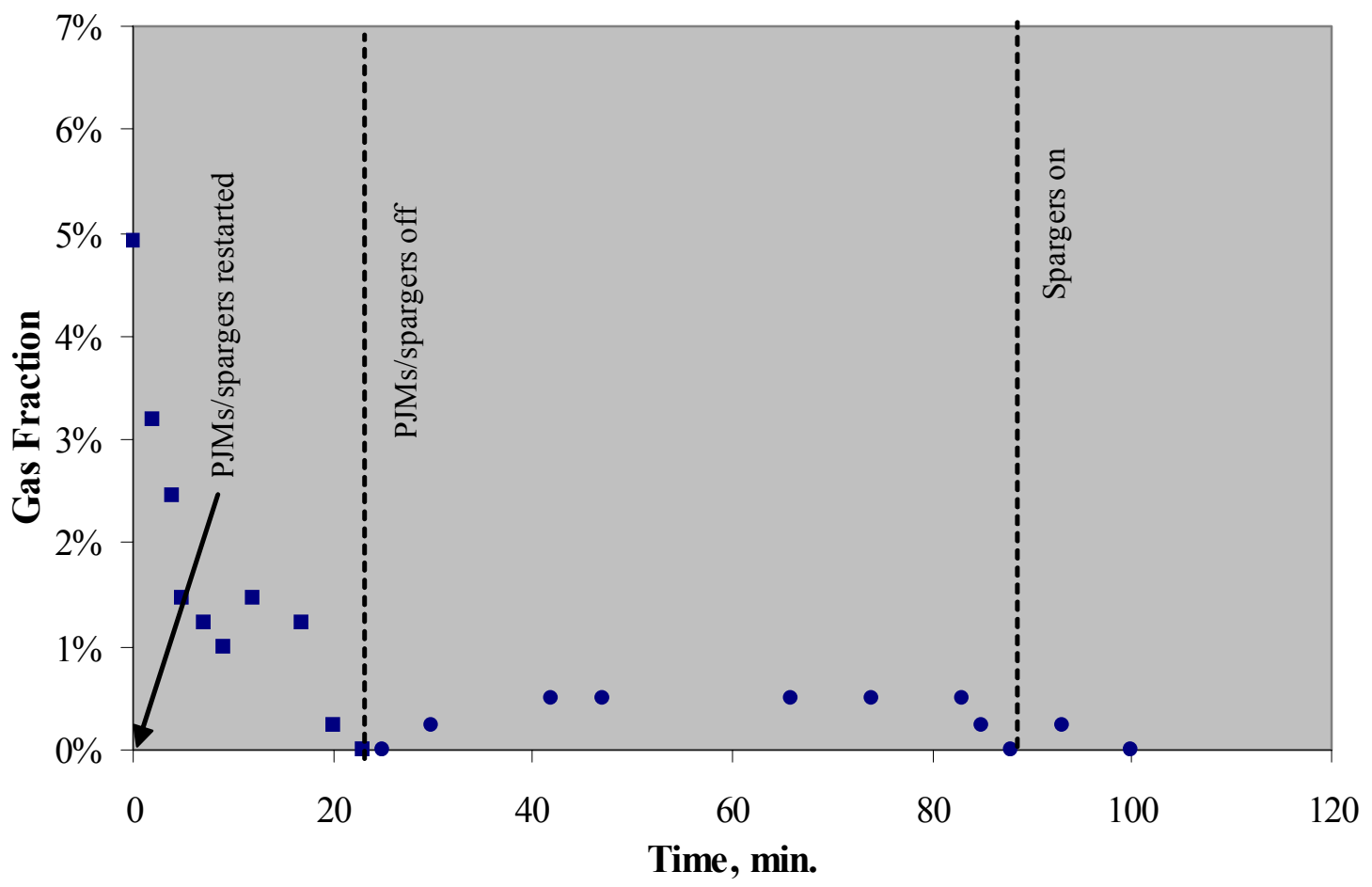

Figure 2-15. Gas Release from Gelled Clay in the CRV Prototype after Gas Holdup in Figure 2-10 (Test E-4, 3 upward and 3 downward 1.5" nozzles + five spargers at $1.8 \mathrm{scfm}$ ea) 
WSRC-TR-2004-00399, REVISION 0

SRNL-RPP-2004-00062, REVISION 0

This page intentionally left blank. 
WSRC-TR-2004-00399, REVISION 0

SRNL-RPP-2004-00062, REVISION 0

\subsection{REFERENCES}

1. Test Specification 24590-HLW-TSP-RT-03-011, Rev. 0, "Pulse Jet Mixer Gas HoldUp and Release Testing at Savannah River," by G. L. Smith, November 25, 2003

2. Test Plan WSRC-TR-2003-00532, "Task Technical and Assurance Plan in Support of the RPP Test Specification, "Pulse Jet Mixer Gas Hold-Up and Release Testing at Savannah River)" by H. N. Guerrero, 12/05/03

3. Test Exception 24590-WTP-TEF-RT-04-006, "Test Exception to Test Plan WSRCTR-2003-00410, SRT-RPP-2003-198, Rev. 0, 'Revised Test Matrix and Direction to Reconfigure and Test in the HLW CRV Prototypic Test Platform to Understand Hybrid Mixing Designs .

4. WTP Project Memorandum CCN 052912 from C Bogaerts/JF Howell to S Khan/C Corriveau, "Fluid Properties for HFP Vessels," March 10, 2003

5. WTP Project Memorandum CCN 065607 from GM Duncan to TF Valentino, "Rheology Design Basis for non-Newtonian Treated Waste," November 17, 2003.

6. WTP Project Memorandum CCN 069099 from S Barnes to G Duncan, "R\&T Response to Engineering Review of AZ-102 HLW Pretreated Sludge Rheological Data and Rheological Recommendation for Consideration," October 17, 2003.

7. Poloski A, O. Bredt, B. Calloway, G. Smith, and H. Smith. 2003. Technical Basis for HLW Vitrification Stream Physical and Rheological Property Bounding Conditions. WTP-RPT-100 Rev. 0, Battelle - Pacific Northwest Division, Richland, WA.

8. Speers RA, KR Holme, MA Tung, and WT Williamson. 1987. "Drilling fluid shear stress overshoot behavior." Rheologica Acta, Vol. 26, pp. 447-452. 